\title{
De Novo Transcriptome Study Identifies Candidate Genes Involved in Resistance to Austropuccinia psidii (Myrtle Rust) in Syzygium luehmannii (Riberry)
}

\author{
Peri A. Tobias, ${ }^{\dagger}$ David I. Guest, Carsten Külheim, and Robert F. Park
}

First and second authors: Sydney Institute of Agriculture, School of Life and Environmental Sciences, University of Sydney, Biomedical Building C81, 1 Central Ave., Australian Technology Park, Eveleigh, NSW 2015, Australia; third author: Research School of Biology, College of Sciences, Australian National University, Canberra, ACT 2601, Australia; and fourth author: Plant Breeding Institute, School of Life and Environmental Sciences, University of Sydney, Private Bag 4011, Narellan, NSW 2567, Australia.

Accepted for publication 9 December 2017.

\begin{abstract}
Austropuccinia psidii, causal agent of myrtle rust, was discovered in Australia in 2010 and has since become established on a wide range of species within the family Myrtaceae. Syzygium luehmannii, endemic to Australia, is an increasingly valuable berry crop. Plants were screened for responses to A. psidii inoculation, and specific resistance, in the form of localized necrosis, was determined in $29 \%$ of individuals. To understand the molecular basis underlying this response, mRNA was sequenced from leaf samples taken preinoculation, and at 24 and $48 \mathrm{~h}$ postinoculation, from four resistant and four susceptible plants. Analyses, based on de novo transcriptome assemblies for all plants, identified significant expression

changes in resistant plants (438 transcripts) $48 \mathrm{~h}$ after pathogen exposure compared with susceptible plants (three transcripts). Most significantly up-regulated in resistant plants were gene homologs for transcription factors, receptor-like kinases, and enzymes involved in secondary metabolite pathways. A putative G-type lectin receptor-like kinase was exclusively expressed in resistant individuals and two transcripts incorporating toll/ interleukin-1, nucleotide binding site, and leucine-rich repeat domains were up-regulated in resistant plants. The results of this study provide the first early gene expression profiles for a plant of the family Myrtaceae in response to the myrtle rust pathogen.
\end{abstract}

Most Australian myrtaceous species have been shown to be vulnerable to infection by the recently reclassified fungal pathogen Austropuccinia psidii (Beenken 2017), causal agent of myrtle rust (Morin et al. 2012; Pegg et al. 2014a). First described in Brazil, A. psidii, an obligate biotroph, was discovered in Australia in 2010 (Carnegie et al. 2010) and has become established on a wide range of species within the Australian Myrtaceae, including 232 taxa from field infections and a further 115 under artificial inoculation (Carnegie et al. 2016; Giblin and Carnegie 2014). Following its first detection on the Central Coast of New South Wales (NSW), A. psidii spread rapidly with records from north of Cairns $\left(16^{\circ} 91^{\prime} \mathrm{S}\right.$ $145^{\circ} 77^{\prime} \mathrm{E}$ ) in Queensland (Pegg et al. 2014b) to west of Melbourne

†Corresponding author: P. A. Tobias; E-mail: peri.tobias@sydney.edu.au

Funding: This work was partially funded by the Australian Government Rural Industries Research and Development Corporation (RIRDC). An Australian Postgraduate Award scholarship was generously provided for P. A. Tobias by the Australian Government and top up scholarships by the University of Sydney and RIRDC.

All raw data are deposited at the National Center for Biotechnology Information (NCBI) as study accession: SRP098851 and BioProject: PRJNA356336. Transcriptome Shotgun Assemblies, all first versions, have been deposited at DDBJ/ EMBL/GenBank under the accessions; GFHK00000000 (R1), GFHT00000000 (R2), GFHS00000000 (R3), GFHO00000000 (R4), GFHN00000000 (S1), GFHM00000000 (S2), GFHL00000000 (S3), and GFMF00000000 (S4).

Author contributions: P.T. designed the research project, conducted the research, undertook the data analysis and wrote the manuscript. C.K assisted with the research design, laboratory work and data analysis. D.G. and R.P. provided advice and support on the research design and assisted with interpreting the biological responses. All authors read and edited the manuscript.

*The $e$-Xtra logo stands for "electronic extra" and indicates that two supplementary figures, two supplementary tables, and one supplementary data file are published online.

(c) 2018 The American Phytopathological Society $\left(38^{\circ} 07^{\prime} \mathrm{S} 144^{\circ} 31^{\prime} \mathrm{E}\right)$ in Victoria (Kriticos et al. 2013). The pathogen has also been reported in Tasmania and the Northern Territory (Westaway 2016). Predictive modeling has determined a potential spread into currently unaffected areas, including Western Australia (Kriticos et al. 2013). There remain concerns for the impact of this new pathogen on commercial industries, such as forestry, cutflower, and native foods, as well as natural ecosystems, dominated by species in the family Myrtaceae (Carnegie and Lidbetter 2012; Glen et al. 2007; Tobias et al. 2015).

Although a species may be susceptible to infection by A.psidii, a small proportion of resistant individuals are usually found in genetically diverse wild populations when tested in controlled inoculations (Morin et al. 2012; Pegg et al. 2014a; Zauza et al. 2010). These variable responses suggest that resistant individuals, when identified, may be useful for replanting and breeding programs. For commercially valuable species, resistant individuals can also be used to develop molecular markers linked to the resistance for germplasm screening (Butler et al. 2016; Mamani et al. 2010) and, particularly in the case of woody plants, extending our knowledge on pathogen defense.

Syzygium luehmannii (F.Muell.) L.A.S. Johnson, commonly named Riberry or small-leaved Lilly Pilly, is a littoral rainforest myrtaceous tree endemic to the east coast of Australia, with a natural distribution from northern NSW to north Queensland. Widely grown as a horticultural specimen, $S$. luehmannii has become an increasingly valuable berry crop, with 2010 farm gate value around A \$100,000 (Clarke 2013). $S$. luehmannii is moderately susceptible to $A$. psidii infection in controlled inoculations, with 60 to $70 \%$ resistant individuals (Morin et al. 2012), thereby potentially reducing crop viability and adding to production costs. The pathogen occurrence on the east coast of Australia incorporates the natural distribution for S. luehmannii and the major propagation and growing regions.

The use of deep-sequencing technologies with messenger RNA provides a method of identifying gene expression changes that are likely to relate to molecular and phenotypic variation, as has been 
shown in several woody plant pathogen interactions to date (Liang et al. 2014; Liu et al. 2013; Mangwanda et al. 2015; Oates et al. 2015). RNA sequencing (RNAseq) enables the scrutiny of gene expression profiles at precise moments in time following perturbation (Wang et al. 2009a). Without a reference genome, the transcriptome is assembled de novo and gene expression comparisons are made between plants contrasting in phenotype for a given trait. Differential expression analysis determines the most highly significant genes that differ between groups (resistant and susceptible), which are then aligned for homologs within external databases. While no reference genome sequence exists for $S$. luehmannii, the published Eucalyptus grandis genome (Myburg et al. 2014), a distantly related species, provides a useful basis for determining gene homologs despite their evolutionary divergence c. 65 million years ago (Thornhill et al. 2015).

Here, wild-sourced S. luehmannii were screened for response to inoculation with $A$. psidii. As differences in the phenotypes of both resistant and susceptible plants are likely to have an underlying molecular basis, gene expression studies were conducted. Once expression profiles were determined, the transcriptomes were screened for variants within two major defense gene families incorporating up-regulated transcripts encoding chitinases and nucleotide binding site and leucine-rich repeat domains (NBSLRR). Differential gene expression analysis of resistant and susceptible $S$. luehmannii individuals provides the first early response host transcriptome profiles following inoculation with A. psidii.

\section{MATERIALS AND METHODS}

Plant material. S. luehmannii seedlings, propagated with seed from endemic parent plants, were sourced from two commercial nurseries based on the north coast of NSW; Buringbar Rainforest Nursery (84 plants) and Firewheel Nursery (50 plants) in February 2015. Plants were approximately 2 months old at time of purchase. Parent plants were located within the natural distribution of the species, on the north coast of NSW, Australia at Pottsville (S 28.38415, E153.56208), and Brunswick Heads (S28.5411, E153.55178), NSW. Plant material was transported to the Plant Breeding Institute Camden (PBI) facility, The University of Sydney,

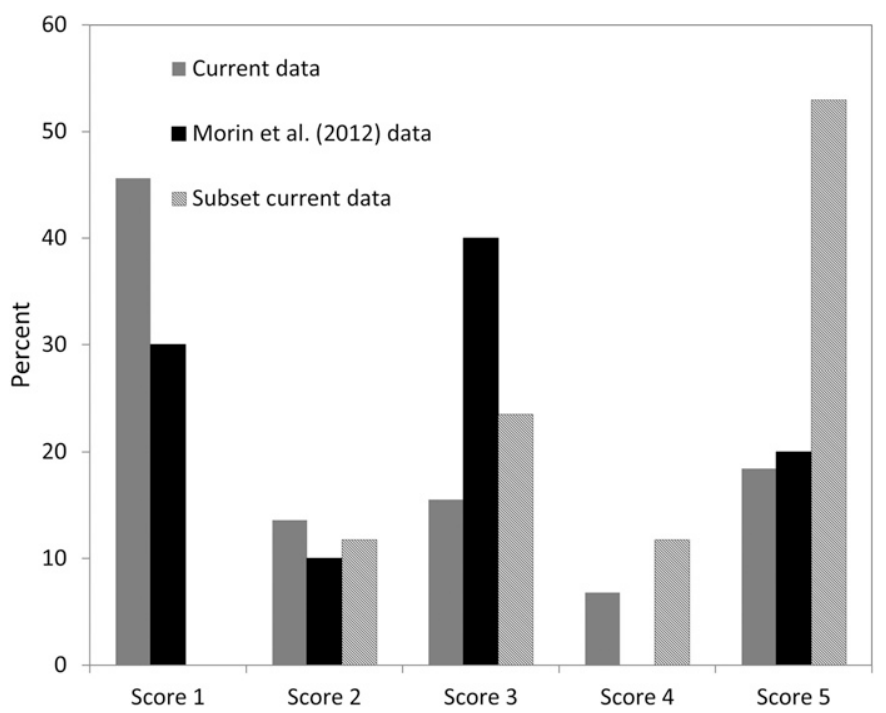

Fig. 1. Percentage of resistant and susceptible Syzygium luehmannii plants in response to inoculation with Austropuccinia psidii based on the current study ( $n=103)$, previous study, $(n=10)$ (Morin et al. 2012), and subset of current study $(n=17)$ (plants that were previously field infected). Scores from 1 (highly resistant) to 5 (highly susceptible) based on system developed by Morin et al. (2012). and plants were cut back to stimulate new growth and potted up with standard potting mix (9:1 composted pine bark/sand) into $100 \mathrm{~mm}$ pots. Plants were kept in poly-glasshouse conditions and drip irrigated at a temperature set to $23^{\circ} \mathrm{C}$. It was noted that 17 plants had $A$. psidii pustule development on arrival at PBI, presumably arising from previous field exposure. These plants were included in the study after cutting off infected material and allowing symptom-free regrowth to develop (approximately 1 month later).

Inoculation with $\boldsymbol{A}$. psidii. Once new pink growth (immature leaves) was visible, $103 \mathrm{~S}$. luehmannii plants were inoculated (30 March 2015) under controlled conditions. At this growth stage, plants presented with approximately five to six new leaves were deemed suitable for inoculation. Urediniospores from a single isolate of $A$. psidii accession 622 (Sandhu et al. 2015) maintained in liquid nitrogen at PBI were placed in $10 \mathrm{ml}$ of Isopar and the mixture was agitated. Spore concentration was calculated using a hemocytometer at $\sim 8 \times 10^{5}$ spores per ml. Aerosol spraying of this inoculum was conducted in a chamber before moving the plants to a dark, humid room where they were incubated at 20 to $22^{\circ} \mathrm{C}$ overnight. Highly susceptible $S$. jambos plants were coinoculated with trial plants as positive controls for rust infection. Following inoculation and overnight incubation, plants were moved into poly-glasshouse conditions and drip irrigated at a temperature that was set to $23^{\circ} \mathrm{C}$.

Scoring for infection. Plants were scored for infection from 1 (highly resistant) to 5 (highly susceptible) at 2 weeks postinoculation based on the scoring system developed by Morin et al. (2012) (Fig. 1). Photographs of plants were taken at 21 days postinoculation using a macro lens (Fig. 2).

Leaf samples were collected and RNA extracted. Leaf samples, one immature leaf per plant, were collected from all specimens at three time points: approximately $2 \mathrm{~h}$ preinoculation, $24 \mathrm{~h}$ postinoculation (hpi) and $48 \mathrm{hpi}$. Samples were removed with sterile sharp scissors and immediately placed in liquid nitrogen before being stored at $-80^{\circ} \mathrm{C}$. Once the plant response phenotypes were established, four resistant plants (score of 2 to $3, \mathrm{HR}$ ) and four susceptible plants (score of 5, extensive pustules) were selected for gene expression studies. Plants were henceforth labeled R1-4 (resistant) and S1-4 (susceptible).

RNA was extracted from leaf samples of the eight selected plants at three expression times making the total number of extractions 24 . Total RNA was extracted using the Sigma-Aldrich Spectrum Total RNA Kit (Sigma-Aldrich, St. Louis, MO), using Protocol A. Leaf tissue $(100 \mathrm{mg})$ was ground in liquid nitrogen with mortar and pestle before proceeding as per the manufacturer's protocol. RNA samples were then purified using a MO BIO PowerClean Pro RNA Cleanup Kit (MO BIO Laboratories, Inc., Carlsbad, CA) and quantified using NanoDrop2000 (Thermo Scientific Inc., Wilmington, DE). Quality of RNAwas assessed by absorption ratios of greater than 2.0 $(260 / 280 \mathrm{~nm})$ and greater than $1.7(260 / 230 \mathrm{~nm})$.

RNA library preparation for sequencing on Illumina. RNA samples ( 24 samples of $\sim 500 \mu$ g each) were prepared for mRNA sequencing using the NEBNext Ultra RNA Library Prep Kit for Illumina (E7530) and NEBNext Ultra Directional RNA Library Prep Kit for Illumina (E7420) (New England Biolabs Inc., Ipswich, MA) according to the manufacturers' protocol. As there is no reference sequence for the species, it was decided to increase fragment sizes to allow for better transcriptome assembly. Size selection from fragment lengths of 300- to 450-bp insert size was based on the recommendations in the manufacturers' protocol. Library concentrations were assessed using Qubit Fluorometric Quantitation and samples diluted to $\sim 3 \mathrm{~nm}$ concentrations before pooling. All bead clean-ups were conducted with GE Healthcare Life Sciences SeraMag SpeedBead Carboxylate-Modified Magnetic Particles (hydrophobic) $15 \mathrm{ml}$ (GE Healthcare Life Sciences, Chicago, IL) except for the initial steps, Chapter 1.2, using NEBNext Oligo d(T) ${ }_{25}$. Sequencing was run using two lanes of an Illumina HiSeq2500 (Illumina Inc., San Diego, CA) at the Australian National University Biomolecular Resource Facility with 150 bp Paired End reads. 
Transcriptome assembly. Transcriptomes for each plant from all samples (preinoculation, 24 and $48 \mathrm{hpi}$ ) were assembled with paired-end reads using Trinity software v2.1.1 (Grabherr et al. 2011) on the University of Sydney high performance computing (HPC) service. These raw reads were then trimmed of adaptors and low-quality reads with Trimmomatic v0.33 (Bolger et al. 2014), within the Trinity platform (Haas et al. 2013), using all standard parameters. Left and right trimmed fastq files, from paired with unpaired reads, were then used to build complete transcriptomes based on all expressed genes.

All eight transcriptomes were clustered using CD-HIT-EST-2D (Fu et al. 2012; Li et al. 2001) into a combined transcriptome representing the $S$. luehmannii species, with sequence identity threshold set at 0.98 and all other default settings. This threshold was determined after a validation step identified that, at 0.95 threshold, two highly conserved sequences for chitinases, present within all individual $S$. luehmannii transcriptomes, were altered in the clustered transcriptome but at 0.98 were faithfully retained. Transcriptomes were combined in pairs from the file with the largest to the smallest number of transcripts. In this way the process was run seven times to make the final clustered fasta file. A bed file, containing a single annotation for each sequence, was created using a Biopython script (Brown 2010). The output file therefore incorporated three columns with the gene identification, a start site of 0 and end site as the length of the transcript.

Read mapping. Trimmed paired with unpaired fastq files from single moments of time $(0,24$, and 48$)$ for each individual plant were then mapped to the merged transcriptome using Bowtie v1.1.2 (Langmead et al. 2009) and sorted, indexed binary alignment map (BAM) outputs created using SAMtools v1.2 (Li et al. 2009). Additionally, reads were mapped to individual transcriptomes and counts for specific gene variants were extracted to enable a comparison with the count data from the merged transcriptome. The data from mapping to individual transcriptomes (R1-4 and $\mathrm{S} 1-3)$ was used to validate expression from the merged transcriptome.

Gene expression analysis. BEDtools v2.24.0 (Quinlan and Hall 2010), with the multiBamCov option, was used to determine raw read counts per transcript, per individual and sample $(0,24$, and 48 hpi). Raw read counts, from resistant versus susceptible plants, were sorted by differential expression (DE) significance using the Bioconductor package, edgeR (Robinson et al. 2009) in R v3.2.4 ( $\mathrm{R}$ Development Core Team 2011). The common dispersion model was used and lists were extracted. It should be noted that the common dispersion values were checked against the tagwise dispersion in edgeR and found to be similarly high (for example, common dispersion estimates of 0.45 ), an indication that variation in abundance for each "gene" between replicates is high. The edgeR derived gene lists were sorted by false discovery rate (FDR) adjusted significance of less than 0.01 . Further lists were created with DE genes below the 0.05 FDR. Lists were submitted to Blast2GO Basic v3.2.7 (Conesa and Götz 2008) using NCBI Blast $\mathrm{nr}$ (nucleotides) for homology searches. The transcripts per million (TPM) were calculated using the transcript length to adjust for reads per kilobase. The log of the TPM values at each time-point were tested for variance using principal component analysis (PCA) in $\mathrm{R}$ v3.2.4. Filtering of transcripts with zero counts in any library reduced the total transcripts used in PCA to 2,614.

Differential expression data visualization. TPM values were used to draw heat maps of DE transcripts using Orange BioLab v.3 (Demšar et al. 2013) data visualizing heat map function. Row names (transcript ID) were removed and cells merged by k-means (50 clusters based on their mean similarity). This permits large numbers of transcripts to be visually displayed but does not reduce the overall visual impact of the expression. The columns were clustered by similarity while rows were clustered with ordered leaves, which maximize the sum of similarities of adjacent elements. PCA graphs were made in R. (v3.2.4) from the filtered TPM (Supplementary Figure S1). Volcano plots were made in R (v3.2.4) with DE data from edgeR results.

Building hidden Markov models. The combined transcriptome for $S$. luehmannii was searched using nucleotide hidden Markov models (HMM) with HMMER v3.1b2 (Johnson et al. 2010). HMMs were developed from the Myrtaceae reference genome, E. grandis (Christie et al. 2016 and Tobias et al. 2017) or NB-ARC domains for the two classes; TIR and CC, and for glycosyl hydrolase (GH18 and GH19) domains of chitinases.

Sequences for each gene/domain thus derived (that is (TIR) NBARC, (CC) NB-ARC, GH18, and GH19) were selected based on the E-value inclusion threshold for full sequences (default at $<0.01$ ). Transcript identifications from the GH18 and GH19 list were used to extract sequences from the Syzygium.fasta using a custom biopython script adapted from (http://biopython.org/wiki/SeqIO). These $S$. luehmannii derived sequences $(7 \times \mathrm{GH} 18,13 \times \mathrm{GH} 19)$ were then independently aligned and used to build species-specific HMMs in accordance with the HMMER manual (Eddy and

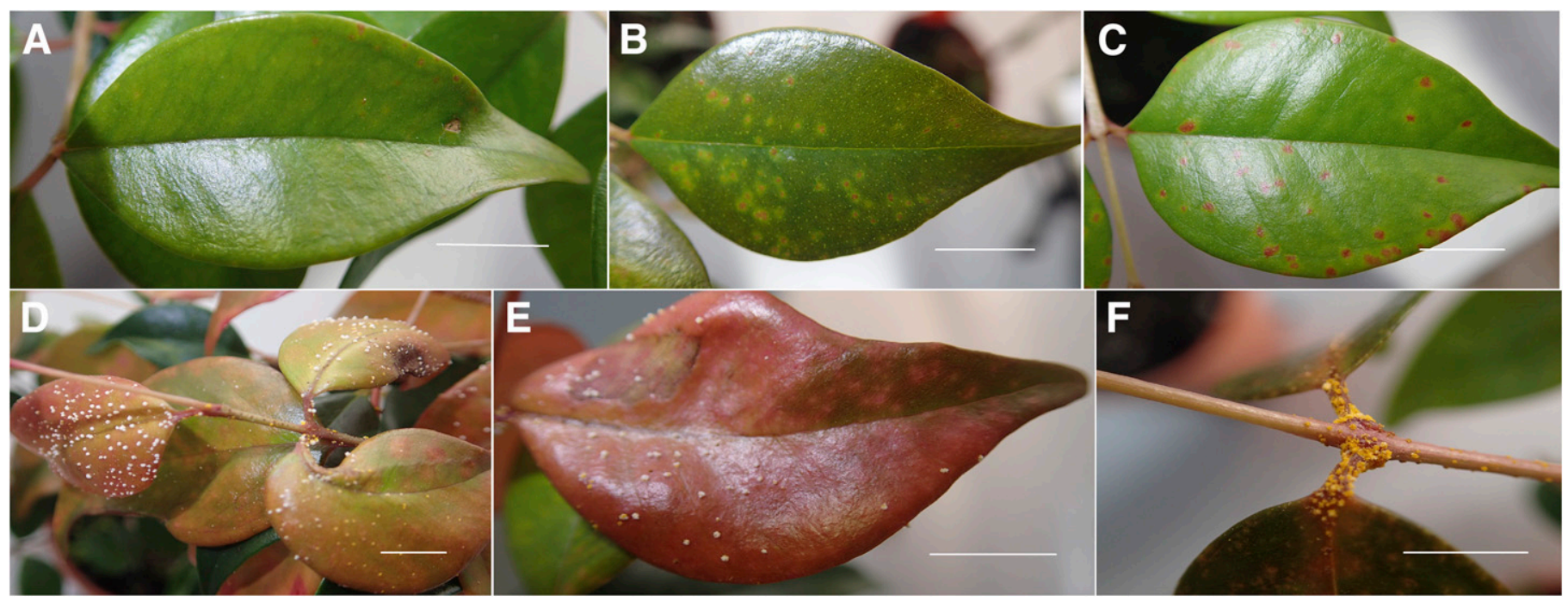

Fig. 2. Responses of Syzygium luehmannii plants to controlled inoculation with Austropuccinia psidii. A, B, and C, Resistance, indicated by localized necrotic regions. D, E, and F, Susceptible plants developed pustules. Photographs were taken 21 days postinoculation. Scale bar $\sim 10 \mathrm{~mm}$. A, Resistant plant 1 (R1); B, R2; C, R3; D, susceptible plant 1 (S1); E, S4; and F, S2. 
Wheeler 2015). E. grandis HMMs derived from (TIR) NB-ARC, (CC) NB-ARC domains were used to search each plant transcriptome. The species-specific nucleotide HMMs were used to screen individual transcriptomes of the eight plants (four resistant and four susceptible) for potential gene candidates. Sequences from each transcriptome were selected based on the HMM E-value inclusion threshold for full sequences.

Gene sequences examined for protein domains. Sequences identified through the HMMs were extracted from individual transcriptome fasta files and six frame translations were made using Geneious version 7.1.8 (Kearse et al. 2012). Sequences derived from (TIR) NB-ARC, (CC) NB-ARC HMMs for each plant were combined and duplicates removed due to overlapping results. The total transcripts from NB-ARC HMMs were considered as one class forthwith. The translated sequences for NB-ARC, GH19 and GH18 transcripts for each plant were submitted to the Pfam server (Finn et al. 2006) in batches for predicted domains at default values (E-value 1.0). Transcript domain data were sorted to determine numbers and types from each plant transcriptome.

NBS-LRR predicted protein structure. A translated sequence representative of a predicted $T I R-N B S-L R R$ differentially expressed in resistant plants was submitted to the I-Tasser server (https://zhanglab.ccmb.med.umich.edu/I-TASSER/) to determine predicted protein structures (Roy et al. 2010). The results from predictive modeling were then manipulated using PyMOL v1.7.4 to identify catalytic sites and domain structures (Supplementary Figure S2).

Translated chitinase sequence alignment and phylogenetic analysis. Chitinase transcripts were aligned with ClustalW (Thompson et al. 1994) and evolutionary relationships inferred using the neighbor-joining tree method (Saitou and Nei 1987) in MEGA7 (Kumar et al. 2016) with all default parameters. E. grandis sequences were included as class identifiers (Tobias et al. 2017) and Arabidopsis thaliana outliers were included in Class III (At5g24090) and Class V (At4g19810) phylogenies.

Primers designed and tested for differentially expressed genes. To validate the presence of putative transcripts that were identified with de novo assembly, significantly differentially expressed transcripts within the functional defense pathway were selected for amplification and sequencing. These included transcripts homologous to the following putative genes in E. grandis: strigolactone receptor D14, phenylalanine ammonia lyase (PAL), respiratory burst oxidase, Class II chitinase (Eucgr.H04034), thaumatin-like protein, disease resistance response protein, Myb46like transcription factor, and leucine-rich (LRR) extensin-like protein. Primers were designed for all of these genes, except for $P A L$, which has important roles beyond defense. Additionally, primers were designed for defense-related genes of interest including the putative Class IA chitinase, a second Class II chitinase (Eucgr.H00455 homolog) and the conserved NB-ARC domain region of the putative Austropuccinia psidii (NBS-LRR) resistance gene 1 (APRI) (Table 1). Additional methods and results related to amplification of defense-related genes are available as Supplementary Data S1.

\section{RESULTS}

Syzygium luehmannii infection responses. Responses to inoculation indicated that $77(75 \%)$ plants were resistant (score 1 to 3 ) and $26(25 \%)$ susceptible (score 4 to 5) (Fig. 1). There were 47 plants $(46.5 \%)$ with no visible symptoms. The presence of localized necrosis, characteristic of the hypersensitive response (HR), indicated a rapid and effective resistant response in 30 plants $(29 \%)$. After 21 days, abundant spore production was apparent on the susceptible plants (Fig. 2D, E, and F) while many resistant plants showed an HR (Fig. 2A, B, and C). Interestingly, five plants showing HR (including Fig. 2A and C) were of the 17 plants that had A. psidii pustules on arrival. The remaining 12 plants that arrived with infection were susceptible (scores 4 and 5) (including Fig. 2D and F). S. jambos plants also developed pustules after 21 days.

Transcriptome assembly. The statistics for each assembled transcriptome, based on all reads from all time-points for each plant, are shown in Table 2. The clustered Syzygium transcriptome, based on merging the eight individual transcriptomes, had 69,736 transcripts. As a comparison, the genome from $E$. grandis has 36,376 predicted protein coding genes and 46,280 protein coding transcripts (Myburg et al. 2014). All raw data are deposited at the National Center for Biotechnology Information (NCBI) as study accession: SRP098851 and BioProject: PRJNA356336. Transcriptome Shotgun Assemblies, all first versions, have been deposited at DDBJ/EMBL/GenBank under

TABLE 1. Primers designed and tested for amplification of Syzygium luehmannii cDNA following inoculation with Austropuccinia psidii

\begin{tabular}{|c|c|c|c|}
\hline Gene & Product size (bp) & Forward & Reverse \\
\hline Class IA chitinase & 244 & CATAACCCACCCCGAGTATG & TCGTTCAAGACAGCCATCTG \\
\hline Class II chitinase A & 349 & CAACCACACCATCTCCGACT & TTCAACACCAGCAGTGCAAG \\
\hline Class II chitinase B & 175 & ТTCТСССССТТСАССТТСТT & GAGGATAACCCGGGAATTGT \\
\hline Thaumatin-like & 241 & CGAGGACATGGAAGAAGAGC & GCAGATTGCACAATCCTCCT \\
\hline Strigolactone receptor & 162 & GGACATGGAGTGCCCTAGAA & CAGGTCCTCTCCTTCGACTG \\
\hline Respiratory burst oxidase & 177 & CCTGTATGTGGGCTTCCTGT & GTTCCCTTCGACGACAACAT \\
\hline LRR extensin & 226 & TCTGGGATTTCACCGGATAG & TCCCCTCGAGCATATCAAAC \\
\hline Disease resistance response & 247 & CGTCTCGTTCCTCTTCTTGC & GTCCAAAGTGACAGGGTCGT \\
\hline Myb46 transcription factor & 228 & CCAACAACACCTCCGAATCT & GGGAGGTCTCATCTCCСTTC \\
\hline
\end{tabular}

TABLE 2. Basic statistics from Trinity assembly of Illumina Hiseq2500 sequenced mRNA extracted from eight biological replicates of Syzygium luehmannii

\begin{tabular}{|c|c|c|c|c|c|c|c|}
\hline Plant ID ${ }^{\mathrm{a}}$ & Total Trinity "genes" & Total Trinity transcripts & $\% \mathrm{GC}$ & $\mathrm{N} 10^{\mathrm{b}}$ & $\mathrm{N} 50^{\mathrm{b}}$ & Median contig length & Total assembled bases \\
\hline R1 & 67,231 & 82,911 & 45.44 & 3,700 & 1,654 & 585 & $81,535,957$ \\
\hline $\mathrm{R} 2$ & 90,033 & 115,368 & 44.85 & 3,899 & 1,696 & 542 & $111,654,245$ \\
\hline R3 & 79,388 & 99,738 & 44.95 & 3,547 & 1,657 & 566 & $96,647,482$ \\
\hline $\mathrm{R} 4$ & 75,463 & 95,357 & 45.09 & 3,913 & 1,733 & 560 & $94,918,068$ \\
\hline S1 & 100,190 & 122,560 & 45.04 & 3,602 & 1,522 & 475 & $106,202,762$ \\
\hline $\mathrm{S} 2$ & 76,751 & 98,166 & 45.05 & 3,631 & 1,604 & 558 & $93,434,753$ \\
\hline S3 & 114,109 & 143,816 & 44.31 & 4,111 & 1,751 & 504 & $137,624,114$ \\
\hline S4 & 87,634 & 113,222 & 44.57 & 3,909 & 1,763 & 576 & $114,735,752$ \\
\hline
\end{tabular}

a $\mathrm{R}=$ resistant, $\mathrm{S}=$ susceptible.

b $\mathrm{N} 10$ and $\mathrm{N} 50=$ minimum length of 10 and $50 \%$ of all assembled contigs . 
the following accessions: GFHK00000000 (R1), GFHT00000000 (R2), GFHS00000000 (R3), GFHO00000000 (R4), GFHN00000000 (S1), GFHM00000000 (S2), GFHL00000000 (S3), and GFMF00000000 (S4).

Expression differences in resistant versus susceptible plants. After mapping the raw reads from each sample $(0,24$, and $48 \mathrm{hpi}$ ) to the $S$. luehmannii combined transcriptome, read counts were compared between resistant and susceptible plants. At preinoculation $(0 \mathrm{~h})$, there were $33 \mathrm{DE}$ genes, of which 14 were higher and 19 lower expressed in resistant plants (Fig. 3A). The fold change and significance of differential expression is presented visually in Figure 4A. Homology was largely found for predicted E. grandis genes based on the National Center for Biotechnology Information (NCBI-nr) BLAST (Supplementary Table S1). Gene homologs that were constitutively more highly expressed (preinoculation) in resistant plants included: G-type lectin
$S$-receptor-like serine/threonine-protein kinase, cytochrome P450, organic cation/carnitine transporter 3-like, extensin-2like, and glucan endo-1,3-beta-glucosidase. Constitutively lower expressed genes in resistant plants were homologs for predicted laccase-9, FRIGIDA, serine carboxypeptidase-like, nonspecific lipid-transfer protein 1-like, and defensin-like protein-1.

At 24 hpi, 53 up-regulated and 10 down-regulated genes were differentially expressed in resistant plants (Figs. 3B and 4B). Based on homology searches, the genes that were most highly upregulated in resistant plants were homologs for NAC (NAM, ATAF $1 / 2$ and CUC2) domain containing protein, MYB $\overline{46}$-like transcription factor, laccase 4-like, cellulose synthase, secondary cell wall synthesis (probable beta-1,4-xylosyltransferase IRX14H), and CRIB (Cdc42/Rac interactive binding motif) domain containing proteins. Also, up-regulated were gene homologs involved in defense including chitinase-like protein 2, respiratory
A

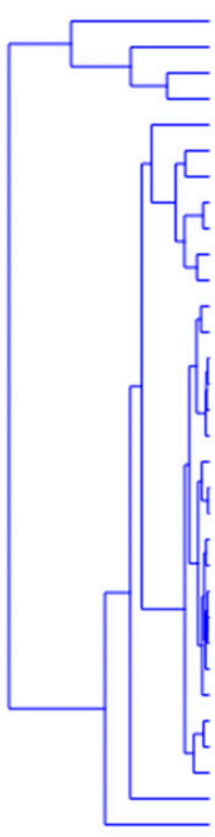

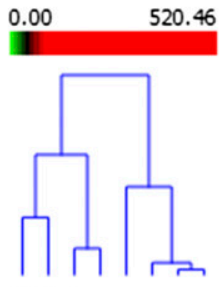

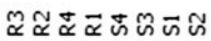

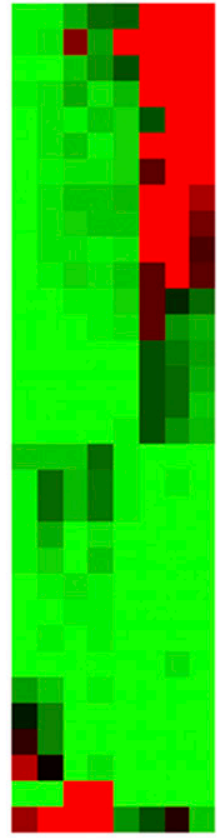

B

B

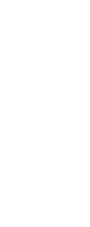

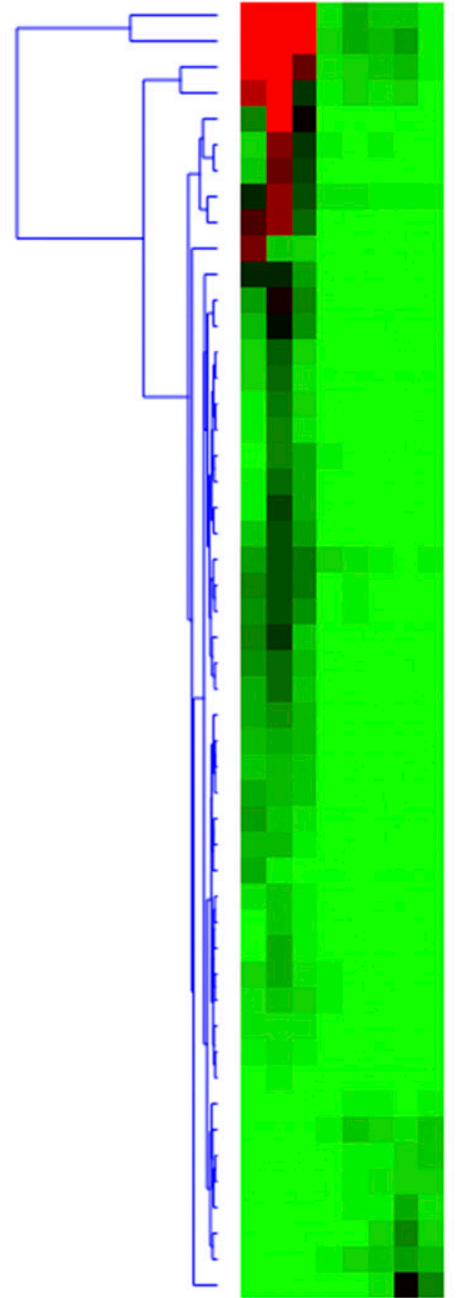

0.00

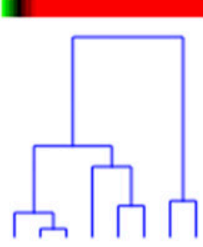

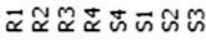
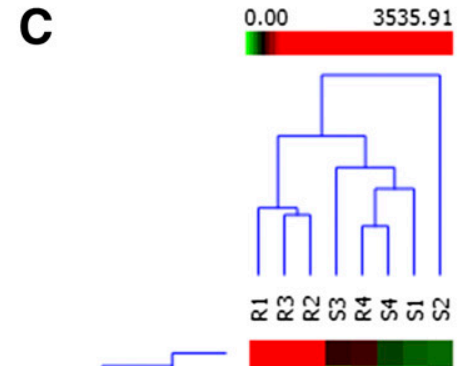

0.00

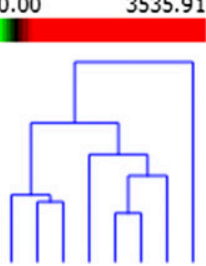

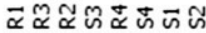

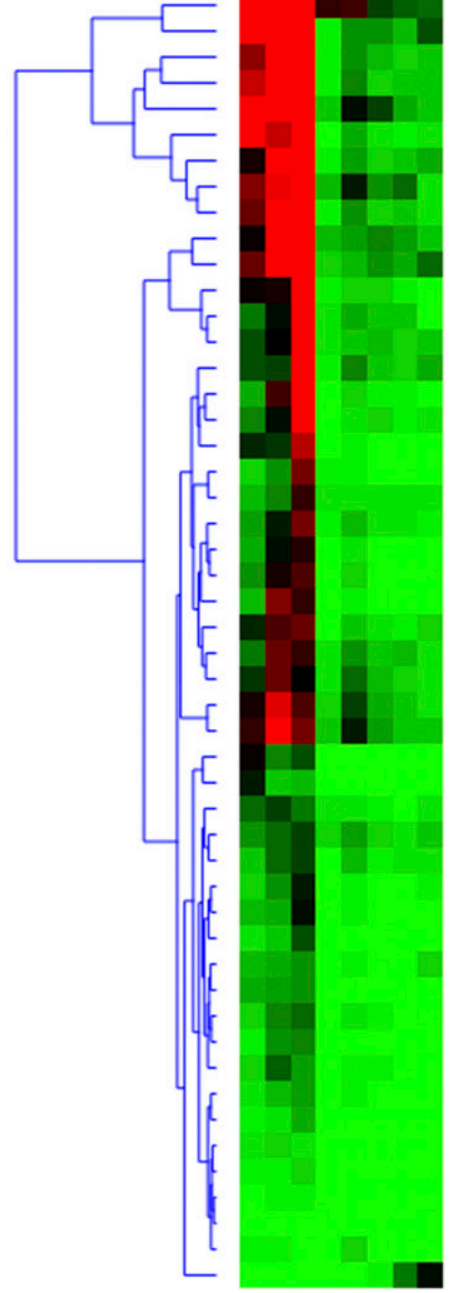

Fig. 3. Significant differential expression (false discovery rate $<0.01$ ) between resistant (R) and susceptible (S) Syzygium luehmannii in response to inoculation with Austropuccinia psidii at $\mathbf{A}$, preinoculation $=33$ genes, $\mathbf{B}, 24 \mathrm{~h}$ postinoculation (hpi) $=63$ genes, and $\mathbf{C}, 48 \mathrm{hpi}=187$ genes. Shaded cells represent transcripts per million. Cells merged by k-means (50 clusters) for image clarity. Full data sets provided in supplementary files. 
burst oxidase, thaumatin-like protein, leucine-rich repeat extensinlike protein, and receptor-like serine/threonine protein kinase. Highest expression in resistant compared with susceptible plants (Fig. 3B, dark gray) was for cellulose synthase A catalytic subunit 7, chitinase-like protein 2, cytochrome P450, and cellulose synthase A catalytic subunit 8. Down-regulated genes in resistant plants included ATP phosphoribosyl transferase and DNA-damage-repair/toleration protein.
At $48 \mathrm{hpi}$, the differences were more pronounced between the groups (Fig. 5) with 185 up-regulated and only one significantly down-regulated gene (histone $\mathrm{H} 2 \mathrm{~A}$ ) in resistant plants (Figs. 3C and 4C). Differential expression largely comprised secondary metabolite pathway and defense-related genes. Based on homology searches, the genes that were most highly up-regulated were MYB46-like transcription factor, carboxylesterase, respiratory burst oxidase, and
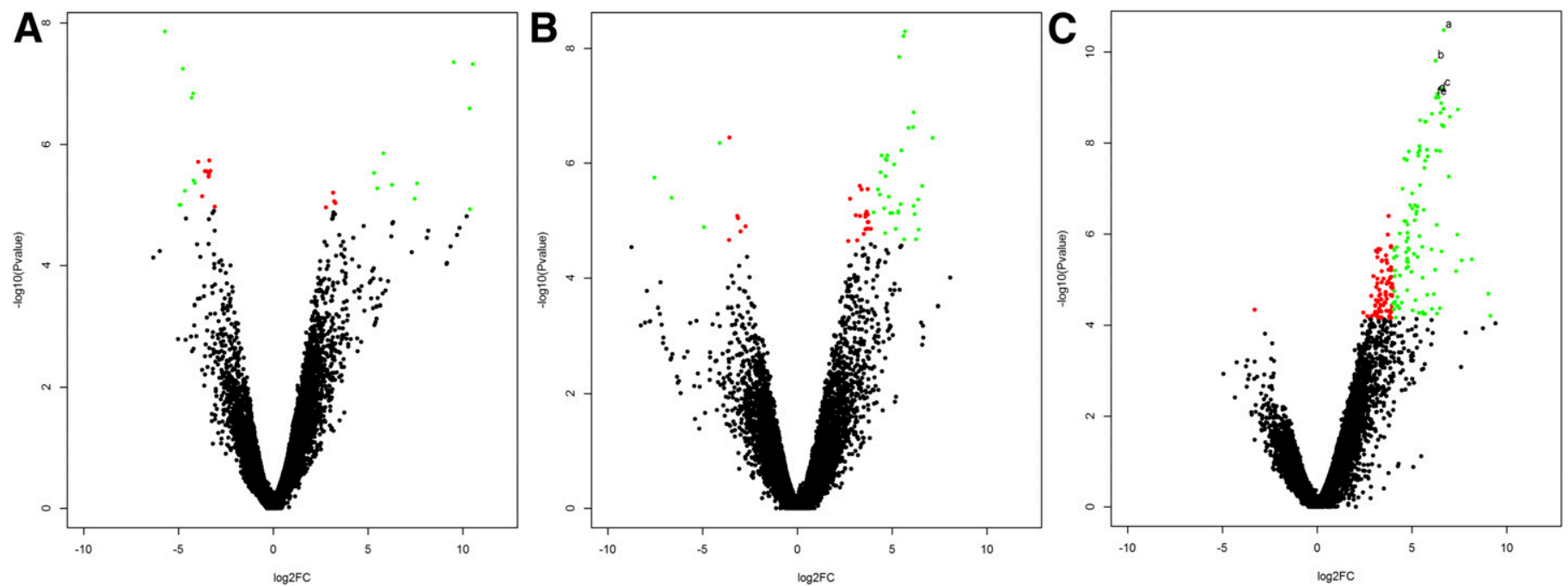

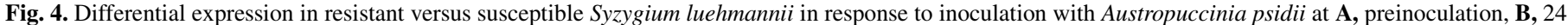

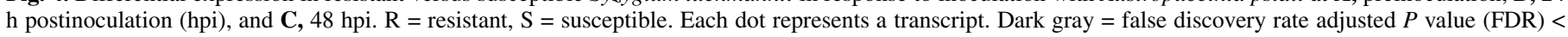

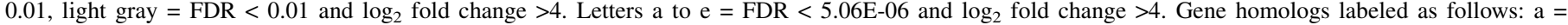
transcription factor MYB46-like, $\mathrm{b}$ and $\mathrm{e}=$ carboxylesterase 12 , and $\mathrm{c}$ and $\mathrm{d}=$ respiratory burst oxidase.
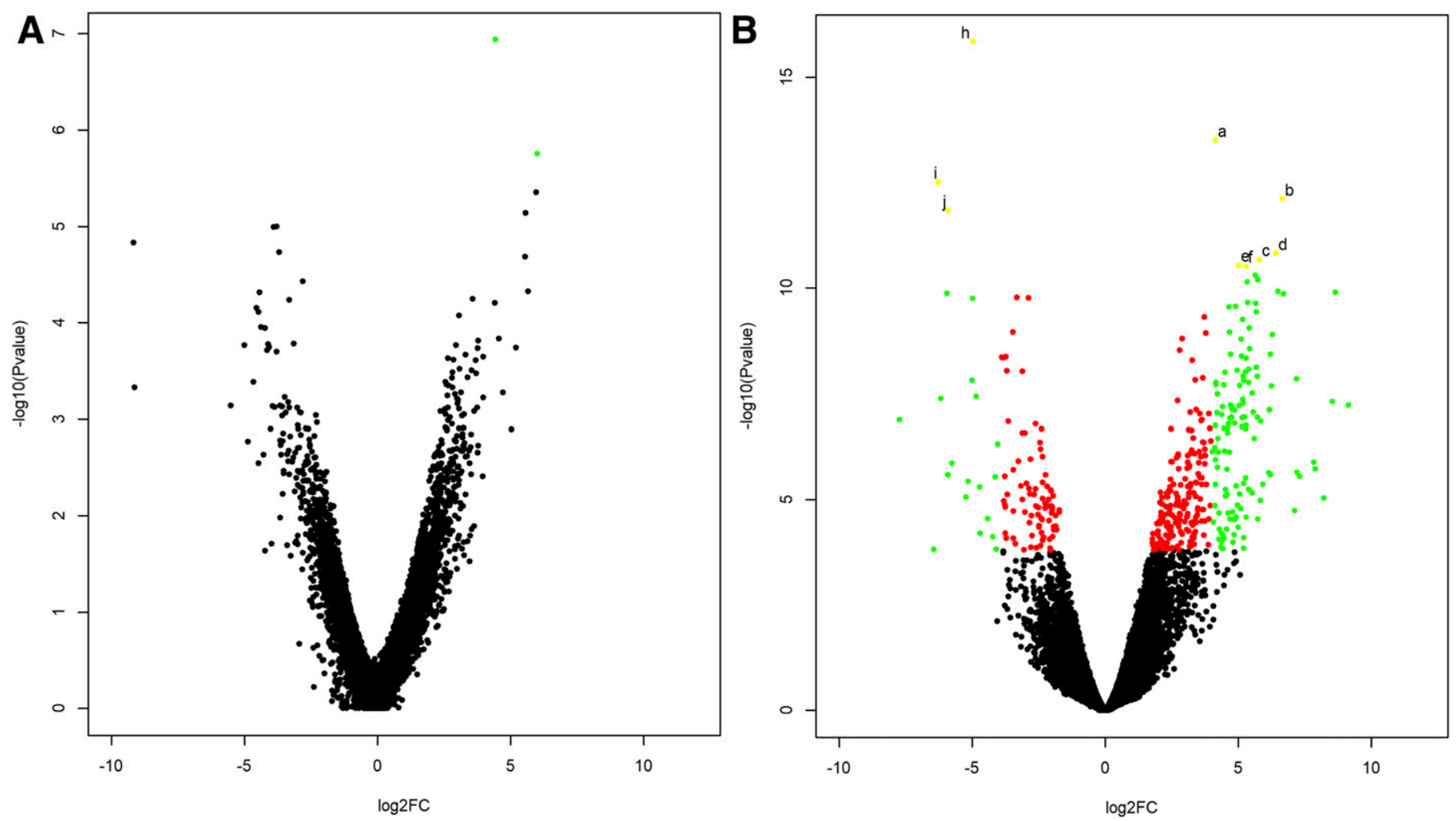

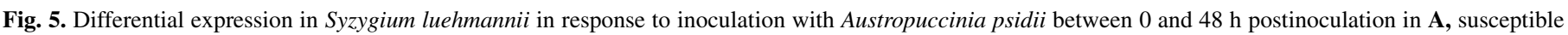

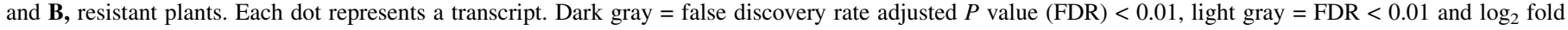

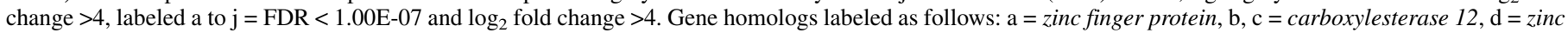

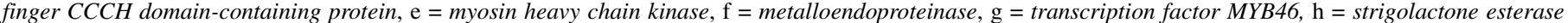
D14, $\mathrm{i}=$ auxin-regulated gene involved in organ size, and $\mathrm{j}=$ uncharacterized. 
leucine-rich repeat extensin protein 6 . The highest expression levels (Fig. 3C, dark gray) were again recorded for cellulose synthase A catalytic subunit 7, fasciclin-like arabinogalactan protein, cellulose synthase A catalytic subunit 8, cellulose synthase A catalytic subunit 4, cytochrome P450, shikimate O-hydroxycinnamoyl transferase, chitinase-like protein 2, phenylalanine ammonia-lyase (PAL), and caffeic acid 3-O-methyltransferase. Notably, cellulose synthase genes were greatly up-regulated in resistant plants, for example at 24 hpi, cellulose synthase A catalytic subunit 7 (mean TPM = 1,723 resistant and 73 susceptible) and cellulose synthase A catalytic subunit 8 (mean TPM $=736$ resistant and 69 susceptible). A strigolactone esterase D14 homolog was significantly downregulated in all plants at $24 \mathrm{hpi}$. While the mean for resistant plants preinoculation was 780 TPM, for susceptible the mean was 358 TPM. After $24 \mathrm{~h}$, the mean was 9.6 TPM for resistant and 8.8 TPM for susceptible. Of interest, one resistant plant (R4) clustered within the susceptible groups for gene expression at both 24 and $48 \mathrm{hpi}$ (Fig. 3B and C).

Expression changes in susceptible plants at 24 and 48 hpi. When comparing gene expression before and after inoculation within susceptible plants, it is evident that there were only a few changes. At $24 \mathrm{hpi}$, six up-regulated genes and one down-regulated gene were found in susceptible plants (Fig. 6A). Based on homology searches, the genes that were most highly up-regulated were E. grandis zinc finger protein CONSTANS-LIKE 2, several E. grandis Late Elongated Hypocotyl (LHY) proteins and E. grandis universal stress protein $A$. The single down-regulated gene was for strigolactone esterase $D 14$, a receptor for the hormone strigolactone, known to have a role in inhibiting shoot branching as well as promoting symbiotic mycorrhizal interactions (Brewer et al. 2013).

At 48 hpi the gene expression differences were fewer with only one up-regulated and no significantly down-regulated genes (Fig. $6 \mathrm{~B})$. The up-regulated gene was zinc finger protein CONSTANSLIKE 2.

Expression changes in resistant plants at 24 and $48 \mathrm{hpi}$. The global gene expression patterns within resistant plants changed substantially following inoculation with A. psidii (Fig. 7). At 24 hpi, 64 up-regulated and 17 down-regulated genes were expressed in resistant plants (Fig. 7A). Based on homology searches, the genes that were most highly up-regulated were homologous to genes encoding zinc finger protein ZAT5 and carboxylesterase 12 . The highest expression levels (Fig. 7A, dark gray [red in online version]) were for an uncharacterized membrane protein At1g06890, cellulose synthase A catalytic subunit 7, fasciclin-like arabinogalactan protein, chitinase-like protein 2, beta-galactosidase, and cytochrome P450. Most significantly down-regulated at $24 \mathrm{hpi}$ was a gene for strigolactone esterase D14, as also determined in susceptible plants.

At $48 \mathrm{hpi}$, the gene expression differences were even greater with 328 up-regulated and 109 down-regulated genes (Fig. 7B). Based on homology searches, the most highly up-regulated genes encoded zinc finger protein ZAT5, carboxylesterase 12, zinc finger C-x8-C$\mathrm{x} 5-\mathrm{C}-\mathrm{x} 3-\mathrm{H}(\mathrm{CCCH})$ domain-containing protein 14 , myosin heavy chain kinase and metalloendoproteinase. The highest expression levels (Fig. 7B, dark gray [red in online version]) were for cellulose synthase A catalytic subunit 7 , fasciclin-like arabinogalactan protein, cellulose synthase A catalytic subunit 4, chitinase-like protein 2, cytochrome P450, phenylalanine ammonia-lyase, caffeic acid 3-O-methyltransferase, S-adenosylmethionine synthase 5, shikimate O-hydroxycinnamoyl transferase, and NADP-dependent glyceraldehyde-3-phosphate dehydrogenase.

The most significantly down-regulated gene was again a strigolactone esterase D14. Other highly down-regulated genes included heat shock protein, Auxin-regulated gene involved in organ size, chaperonin 60 subunit beta 4, high affinity nitrate transporter, F-box/LRR-repeat protein 14, and RADIALIS-like 1. Clustering indicates that individual plant expression patterns are more closely aligned preinoculation compared with both 24 and 48 hpi, with R4 indicating different expression to the other plants.

Predicted NBS-LRR and chitinase transcripts within S. luehmannii. Multiple transcripts were identified for NBS-LRR and GH18 and 19 transcripts within all plants (Table 3). Many translated NB-ARC sequences incorporated fused TIR domains (PF01582.18) as well as LRR domains, predominantly LRR8 (PF13855.4), and Jacalin domains, a mannose binding lectin (PF01419.15). Additional fused domains were highly varied (Supplementary Table S2) with several NB-ARC domains fused with transcription factor (TF) domains such as zinc finger (zf) BED and zf reverse transcription (RVT) domains. Protein tyrosine kinase domains (PF07714.15) and Ras domains (PF00071.20), both important in cellular signaling, were also present across plants. Fused RPW8 domains (PF05659.9), known as broad-spectrum powdery mildew resistance gene domains, were present as a small class of putative NBS-LRR-type transcripts. Of the translated transcripts identified with the GH18 HMM, many were found to contain alternative domains and the GH18 catalytic domain was absent. These sequences were omitted from further analysis. An additional fused domain for GH19 chitinases was the RNA polymerase Rpb8 subunit (PF03870). This was determined within

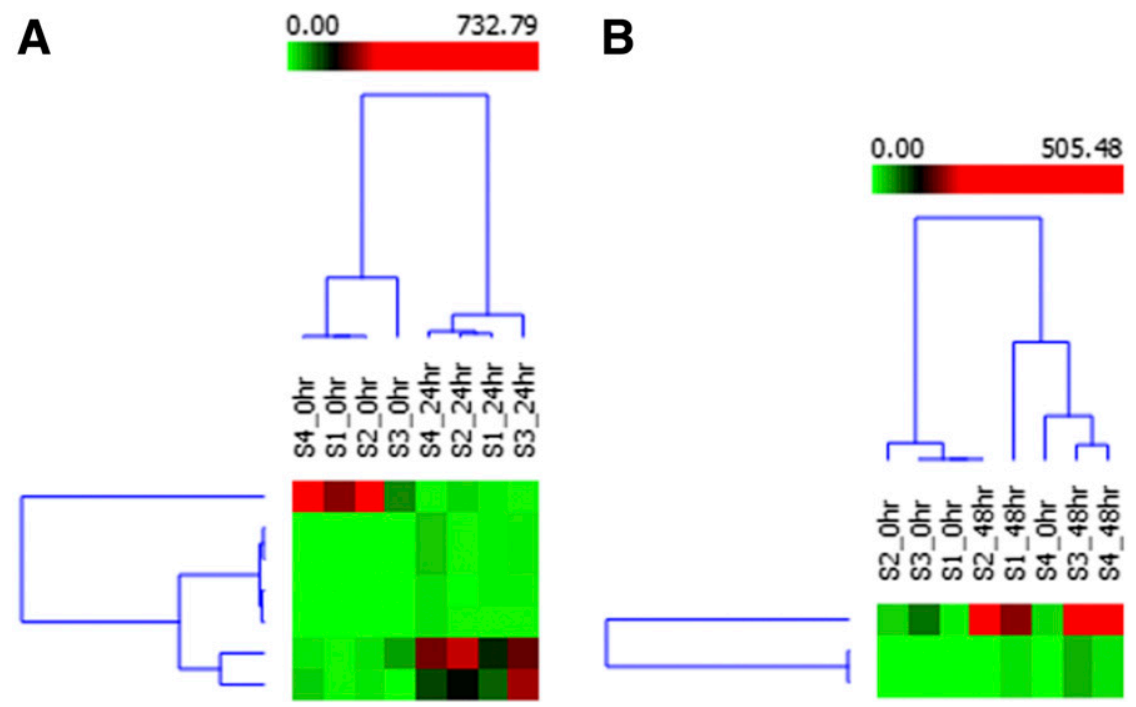

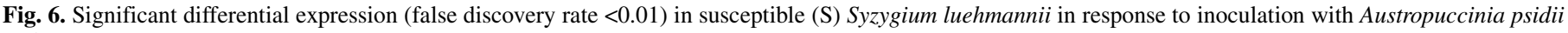
at $\mathbf{A}, 24 \mathrm{~h}$ postinoculation (hpi) $=7$ genes and $\mathbf{B}, 48 \mathrm{hpi}=3$ genes. Shaded cells represent transcripts per million. 
five of the transcriptome assemblies (Table 3), though absent in the merged Syzygium transcriptome.

Differential expression of NB-ARC domain containing transcripts. All differentially expressed NB-ARC domain containing transcripts, within the merged transcriptome were visualized (Fig. 8). At $48 \mathrm{hpi}$, two significantly up-regulated Tobacco mosaic virus resistance gene $N$ homologs were identified in resistant plants, as can be seen in Figure 8C $(n=224)$. While no clear differential expression is seen between resistant and susceptible plants preinoculation (Fig. 8A, $n=230$ ), the two transcripts with the greatest fold change difference both incorporate NB-ARC with fused Jacalin-type domains (PF01419.15). A pattern is evident at $24 \mathrm{hpi}$, though the greatest change is the down-regulation of two transcripts (Fig. 8B, $n=235$ ). The most highly up-regulated gene at $24 \mathrm{hpi}$ is the same Tobacco mosaic virus resistance gene N homolog transcript most significantly up-regulated at $48 \mathrm{hpi}$, and here named putative $A$. psidii resistance gene (APR) 1 and 2 .
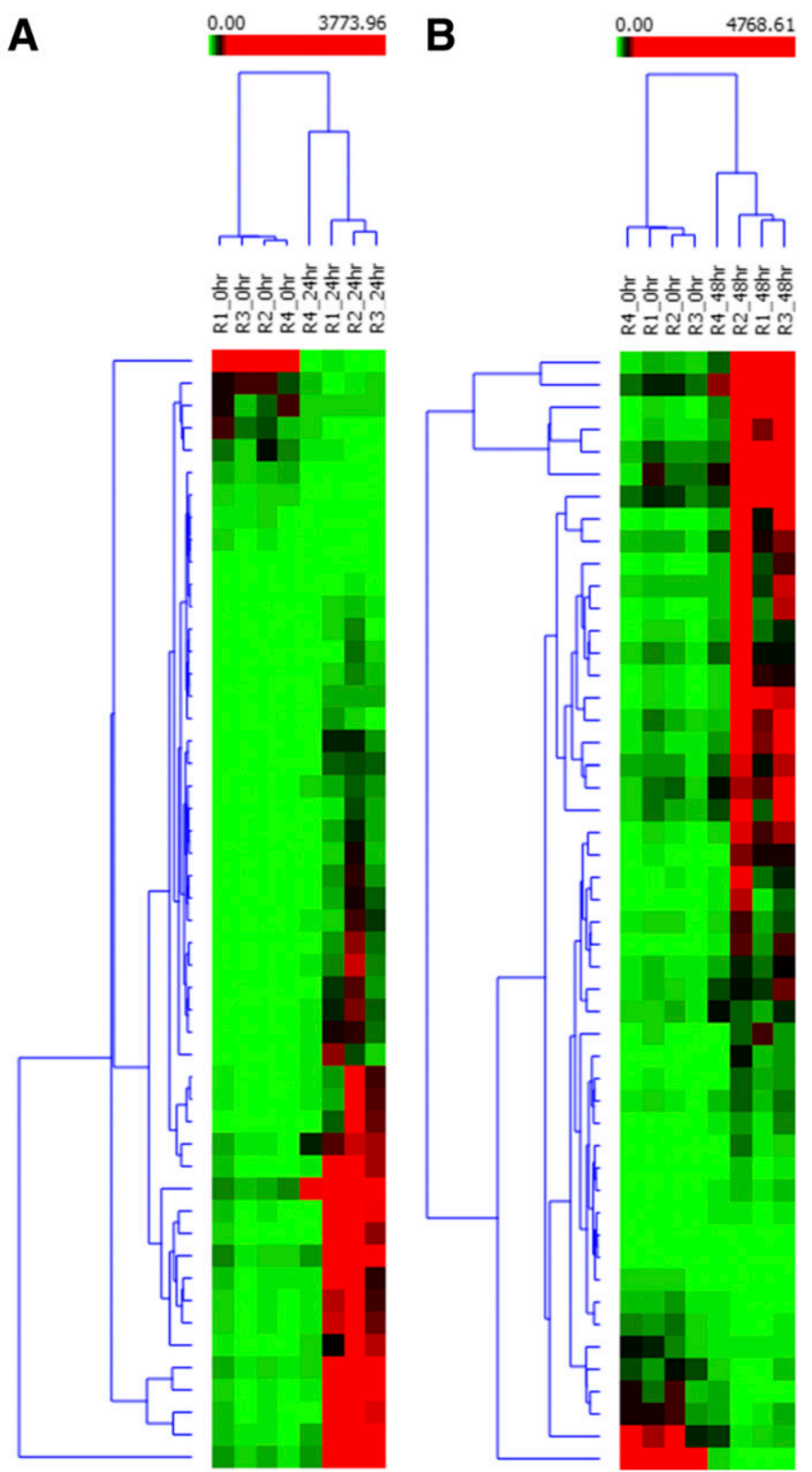

$\vec{\alpha} \mathcal{Q} \mathscr{\alpha} \dot{\alpha} \vec{\alpha} \mathscr{\alpha}$

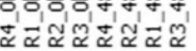
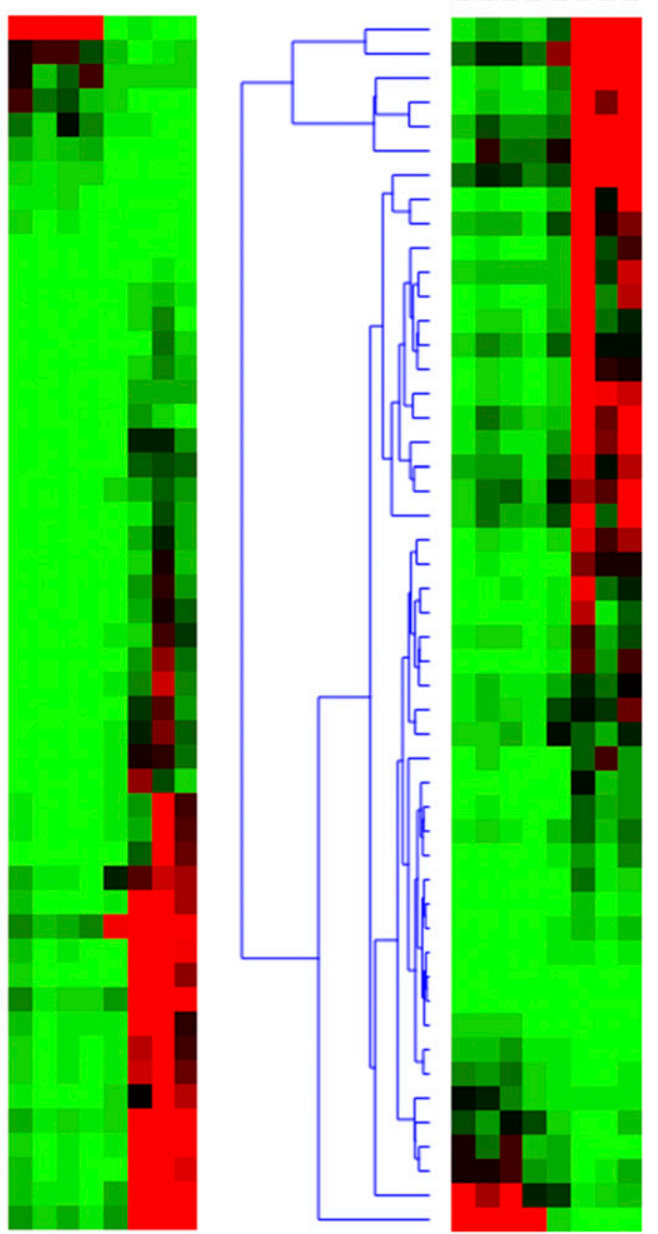

Fig. 7. Significant differential expression (false discovery rate $<0.01$ ) in resistant (R) Syzygium luehmannii in response to inoculation with Austropuccinia psidii at $\mathbf{A}, 24$ h postinoculation (hpi) $=81$ genes and $\mathbf{B}, 48 \mathrm{hpi}=438$ genes. Shaded cells represent transcripts per million. Cells merged by k-means (50 clusters) for image clarity. Full data sets provided in supplementary files.
A predicted protein model for the translated transcript of $A P R$ from I-Tasser (Roy et al. 2010) indicates the conserved regions for ATP binding within the NB-ARC domain and the horse-shoe shaped leucine-rich repeat structure present. The closest homologs within the E. grandis genome data (v2.0) from Phytozome (Goodstein et al. 2012) are two predicted TIR-NBS-LRR genes on chromosome three (Eucgr.C01654 and Eucgr.C01968). Other close homologs included genes located within the Puccinia psidii resistance gene 1 (Pprl) locus (Mamani et al. 2010), estimated at around 52,900,000 bp on chromosome three (Kullan et al. 2012). Specifically, one homolog within the predicted Pprl locus was for Eucgr.C02749, currently unannotated.

NBS-LRR and Class II chitinase expression from individual transcriptomes. Reads mapped to the combined transcriptome were compared with mapping to individual transcriptomes for upregulated NBS-LRR and chitinase transcripts and indicated similar trends, thereby supporting the initial differential analysis (Fig. 9). However, it was determined that $A P R 1$ and $A P R 2$ expression within the individual plant transcriptomes was higher for both resistant and susceptible (Fig. 9A and B).

Expressed chitinase classes identified. The aligned translated Syzygium GH18 and GH19 sequences fell within previously identified E. grandis chitinase Classes I to V (Fig. 10A, B, and C). All plant transcriptomes had a single copy of the GH19 Class I chitinase and only one isoform was determined for this "gene", confirming it as Class IA due to the presence of a C-terminal vacuolar targeting sequence (Tobias et al. 2017). Two translated GH19 sequences (Fig. 10A, Syzygium 5 and 6), a Class I chitinase and the very highly up-regulated Class II chitinase within resistant plants, indicate a high degree of conservation across all plants when aligned (data not shown). Phylogenies were conducted separately for GH18 Class III and V (Fig. 10B and C) due to a high degree of sequence divergence. Of interest two isoforms of a Class $\mathrm{V}$ chitinase (Syzygium 15a and b) incorporating a fused protein tyrosine kinase domain (PF07714) were expressed within all plants.

Primers amplify products. Primers were successfully tested for a subset of the identified putative genes. Gel electrophoresis of amplified products indicated clean bands for amplicons of the putative homologs in both resistant and susceptible plants of Class II chitinase (Syzygium 6, Fig. 10), thaumatin-like protein, strigolactone receptor D14, Class II chitinase (Syzygium 8, Fig. 10), disease resistance response protein, Myb46 transcription factor (24 hpi cDNA), Class IA chitinase, and LRR extensin-like protein (48 hpi cDNA). The two APRl primer pairs did not amplify products in any of the plants using preinoculation cDNA. PCR of putative respiratory burst oxidase and Class IA chitinase genes from 48 hpi cDNA amplified multiple sized amplicons indicating possible splicing variants or genomic DNA contamination. Sequencing of amplicons identified minor sequence variations though these did not correlate with resistant or susceptible phenotypes and might represent heterozygosity.

\section{DISCUSSION}

S. luehmannii shows promising resilience to controlled inoculation with the new encounter pathogen, A. psidii. The responses concur broadly with the smaller sample of 10 plants previously tested (Morin et al. 2012) (Fig. 1). While susceptibility was shown for $25 \%$ of tested plants, $75 \%$ were resistant. Although $46 \%$ of plants showed no symptoms, it was suspected that leaf growth stage may have been a factor, as predominantly new growth is susceptible to A. psidii. All plants were selected for the trial based on the presence of new growth, but minor variations mean that these plants cannot confidently be assessed as resistant from a single inoculation. However, the presence of localized necrosis, characteristic of $\mathrm{HR}$, indicated a rapid and effective resistant response in $29 \%$ of plants. It is of interest that the plants were previously field exposed to $A$. psidii, which suggests a possible priming effect, 
particularly as controlled inoculation was within 1 month of arrival. Systemic acquired resistance (Fu and Dong 2013), whereby previous broad-spectrum exposure to pathogens primes plants for rapid responses to subsequent exposure, provides only a limited explanation. Proportions of plants that reacted with HR indicate that, even if this is the result of priming, not all plants are capable of such effective resistance. Phenotypes for resistance were selected based on HR and the subsequent results of RNAseq analyses indicate that this response has a molecular basis.

Syzygium luehmannii gene expression in response to A. psidii inoculation was examined in two key ways; by comparing significant differential gene regulation between the resistant and susceptible plants and within the resistant and susceptible plants only. We determined that resistant phenotypes have distinct and highly significant gene expression differences (Fig. 3). In particular, the identification of genes involved in defense regulation and genes within the phenylpropanoid pathway appear to be important. The PCA indicates that, though resistant plants cluster more closely before inoculation, the pattern is less distinct between phenotypes after inoculation. Interestingly, within the heatmaps (Fig. 3B and C), resistant plant number four (R4) clustered with the susceptible plants after inoculation, despite an apparent resistant phenotype.
Perhaps also of interest, the R4 plant did not thrive after the initial resistant phenotype and later succumbed to scale insect infestation. It is possible that this plant had a delayed response to infection that still permitted a halting of disease progression.

Resistant plants recognize the pathogen. Crucial to resistant phenotypes is the early recognition of pathogen invasion, which in turn triggers downstream defense responses often leading to a hypersensitive response. Resistant $S$. luehmannii plants appeared to rapidly recognize pathogen incursion. Supporting this finding, resistant plants expressed higher numbers of receptors at all time points. Additionally, a transmembrane receptor, putative $G$-type lectin S-receptor-like serine/threonine-protein kinase (lectin$R L K$ ), significantly differentially expressed in resistant phenotypes prior to inoculation, was present in all resistant and absent from all susceptible plant transcriptomes. This finding suggests a possible role for the lectin-RLK in the initial recognition process. It is conceivable that the carbohydrate-binding function of the lectin-RLK receptor is similar to the mannose-binding property of the rice (Oryza sativa) $\mathrm{Pi}-\mathrm{d} 2$ gene product, which confers resistance to the fungal pathogen, Magnaporthe grisea (Chen et al. 2006).

After inoculation, resistant plants significantly increased receptor expression. Notably, two isoforms of a putative cytoplasmic

TABLE 3. Predicted domains of nucleotide binding site and leucine-rich repeat domains (NBS-LRR) and glycosyl hydrolase (GH)18 and GH19 chitinase identified within Syzygium luehmannii transcriptomes using hidden Markov models ${ }^{\mathrm{a}}$

\begin{tabular}{|c|c|c|c|c|c|c|c|c|c|}
\hline Domain & $\mathrm{R} 1$ & $\mathrm{R} 2$ & R3 & $\mathrm{R} 4$ & $\mathrm{~S} 1$ & $\mathrm{~S} 2$ & $\mathrm{~S} 3$ & S4 & SL \\
\hline \multicolumn{10}{|l|}{ NBS-LRR } \\
\hline NB-ARC & 696 & 1,039 & 905 & 509 & 921 & 742 & 492 & 1,177 & 659 \\
\hline LRR & 30 & 492 & 25 & 29 & 50 & 54 & 34 & 50 & 31 \\
\hline Pkinase & 5 & 3 & 0 & 0 & 8 & 0 & 1 & 3 & 5 \\
\hline Jacalin & 18 & 7 & 62 & 50 & 8 & 11 & 0 & 25 & 16 \\
\hline zf-RVT & 2 & 7 & 0 & 0 & 0 & 0 & 1 & 2 & 2 \\
\hline RPW8 & 7 & 6 & 6 & 2 & 5 & 5 & 11 & 4 & 7 \\
\hline \multicolumn{10}{|l|}{ Glycosyl hydrolase } \\
\hline GH19 & 2 & 21 & 12 & 9 & 13 & 21 & 28 & 11 & 5 \\
\hline GH19+CBD & 3 & 5 & 5 & 3 & 14 & 5 & 5 & 10 & 3 \\
\hline GH19+GH19+CBD & 4 & 3 & 2 & 1 & 1 & 2 & 2 & 2 & 4 \\
\hline GH19+CBD+RNApol & 0 & 1 & 2 & 0 & 1 & 0 & 1 & 1 & 0 \\
\hline GH18 & 6 & 7 & 6 & 7 & 7 & 8 & 7 & 14 & 5 \\
\hline
\end{tabular}

${ }^{a}$ CBD = chitin binding domain, RNApol = DNA dependent RNA polymerase subunit, $\mathrm{R}=$ resistant, $\mathrm{S}=$ susceptible, and SL = combined transcriptome.
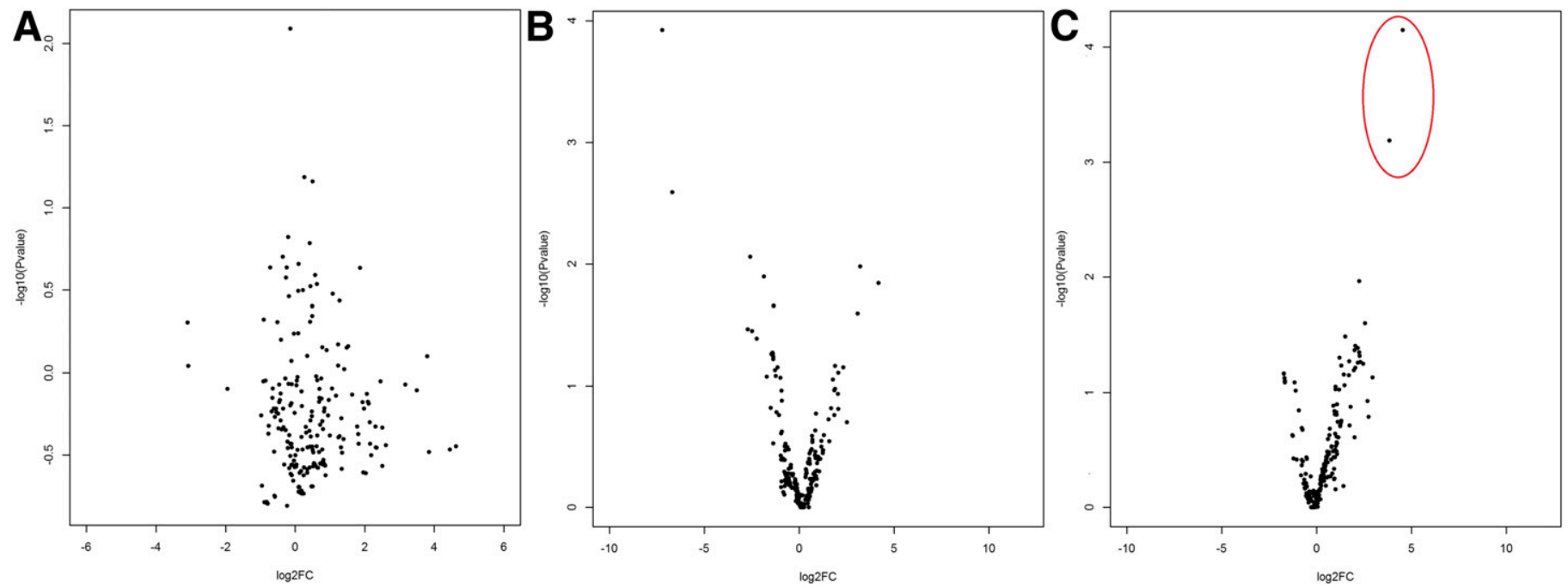

Fig. 8. Differential expression of the NB-ARC domain containing transcripts between resistant versus susceptible Syzygium luehmannii plants inoculated with Austropuccinia psidii at A, preinoculation, B, $24 \mathrm{~h}$ postinoculation (hpi), and C, 48 hpi. Transcript counts based on the combined Syzygium luehmannii transcriptome. The two transcripts that are significantly up-regulated at $48 \mathrm{hpi}$ (circled) within resistant plants (C) correspond to two isoforms of a TIR-NBS-LRR transcript (APR1 and $A P R 2)$. 
receptor of the TIR-NBS-LRR-type (Fig. 8), and here named Austropuccinia psidii resistance genes 1 and 2 (APR1 and APR2), were significantly up-regulated at $48 \mathrm{hpi}$ (FDR 0.0102 and 0.0491). Of key interest the $A P R 1$ and $A P R 2$ transcripts are homologs of E. grandis putative NBS-LRR genes (Christie et al. 2016) within the predicted Pprl locus on chromosome three (Kullan et al. 2012; Mamani et al. 2010). The closest homologs within the E. grandis genome data (v2.0) from Phytozome (Goodstein et al. 2012) are two predicted TIRNBS-LRR genes on chromosome 3 (Eucgr.C01654 and Eucgr.C01968). Other close homologs were also located within the Pprl locus including Eucgr.C02749, currently unannotated, but identified as highly expressed in E. grandis in two biotic studies (Christie et al. 2016). The results suggest that these genes may indeed have a role in $A$. psidii resistance within distantly related myrtaceous species.

A study comparing gene expression in resistant versus susceptible Pinus monticola in response to White pine blister rust (Cronartium ribicola) also reported differential expression of two $N B S$-LRR genes and a receptor-like kinase (RLK) (Liu et al. 2013). It would be interesting to investigate these specific transcripts' expression in other Myrtaceae plants that display resistance to A. psidii. Allelic variants may be important in this response by permitting recognition of diverse pathogens, particularly if NBSLRR dimers functionally interact as has been determined in other plant-microbe interactions (Césari et al. 2014; Saucet et al. 2015).

Resistant plants respond actively to the pathogen. Following perception, suites of genes involved in effective defense are significantly up-regulated in resistant versus susceptible plants. Cascading responses are initiated by receptor-like kinases and mitogen-activated protein kinase 2 , both significantly up-regulated in resistant plants. The up-regulation of such genes indicates that they are actively triggering the key responses such as transcription factors, (including NAC-domain containing proteins, MYB46, and Zinc finger ZAT5), to enable defense gene transcription. NAC are the most up-regulated genes in resistant versus susceptible plants at 24 hpi and are highly DE at 48 hpi. NAC domain containing transcription factors have been experimentally validated as important in biotic response (Wang et al. 2009b). A MYB46 transcription factor was shown to control secondary cell wall cellulose synthases directly (Kim et al. 2013). Notably, cellulose synthase genes were greatly upregulated in resistant plants suggesting that cell wall fortification is an important response to the pathogen. A strigolactone esterase D14 homolog, coding for a hormone receptor known to have a role in inhibiting shoot branching as well as promoting symbiotic mycorrhizal interactions (Brewer et al. 2013), is significantly down-regulated in all plants, even susceptible, at $24 \mathrm{hpi}$. The magnitude of this receptor down-regulation is notable and points to a mechanistic response to the pathogen.

Significantly up-regulated defense transcripts also include respiratory burst oxidase and pathogenesis-related proteins, chitinaselike protein 2 and thaumatin-like protein. In particular, the transcripts for chitinase were very highly expressed at 24 and 48 hpi in resistant plants. Chitinases are enzymes involved in the catalytic hydrolysis
A

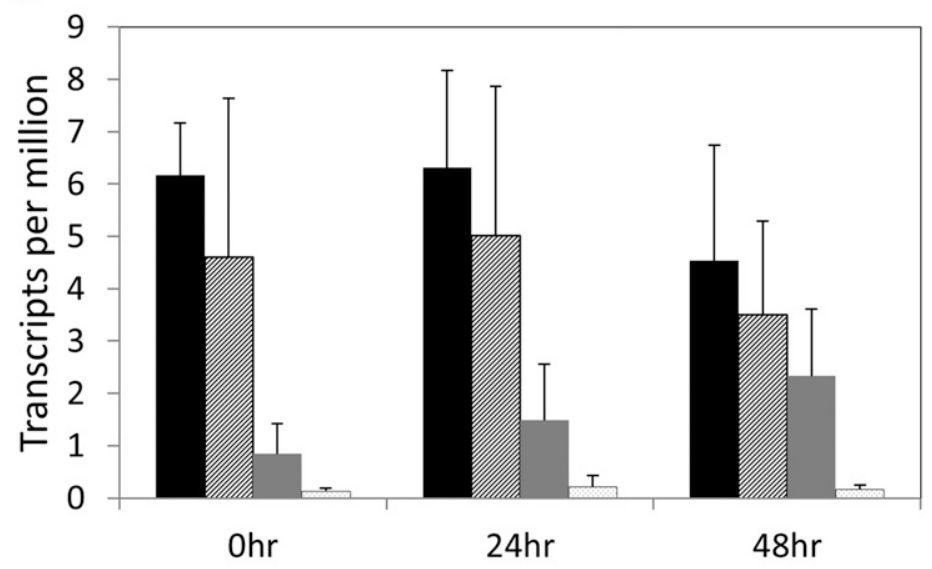

C

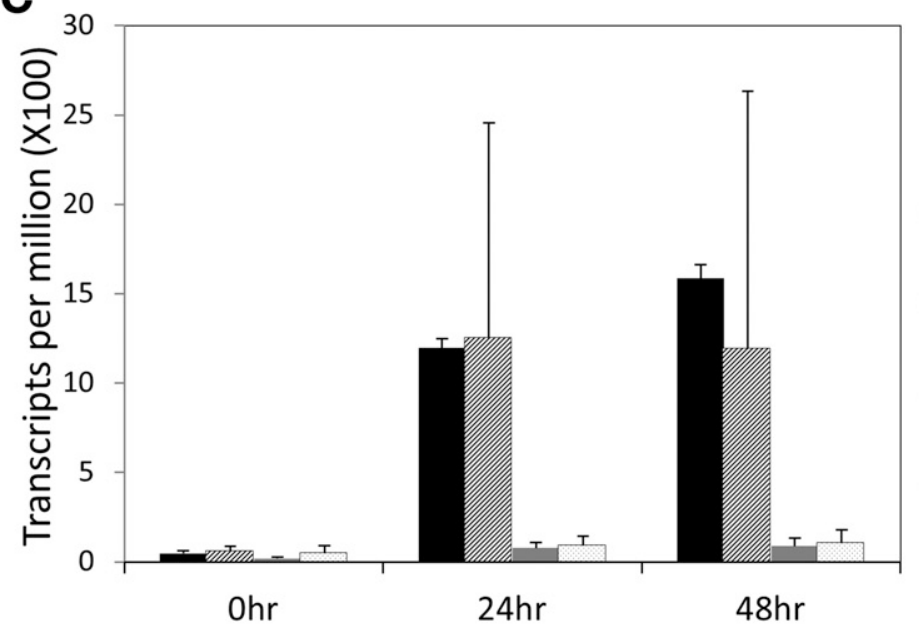

B

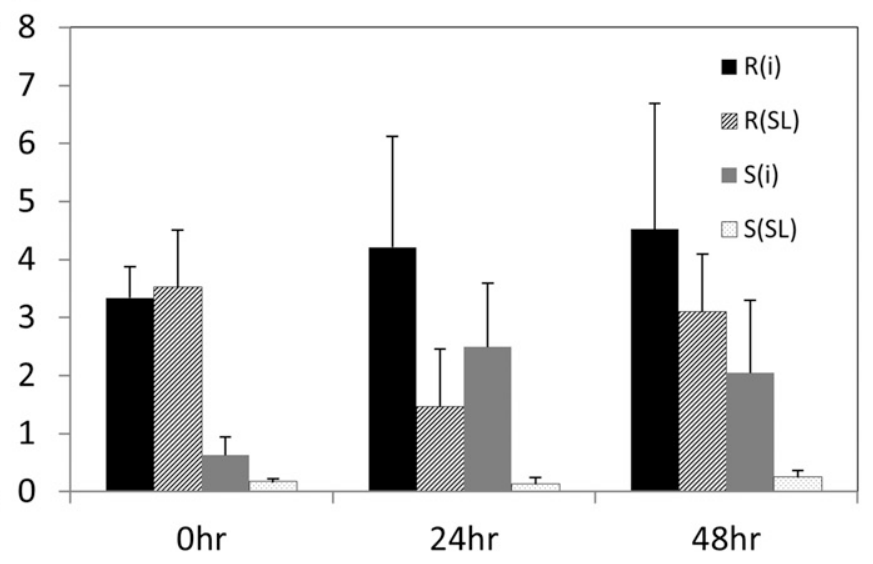

D

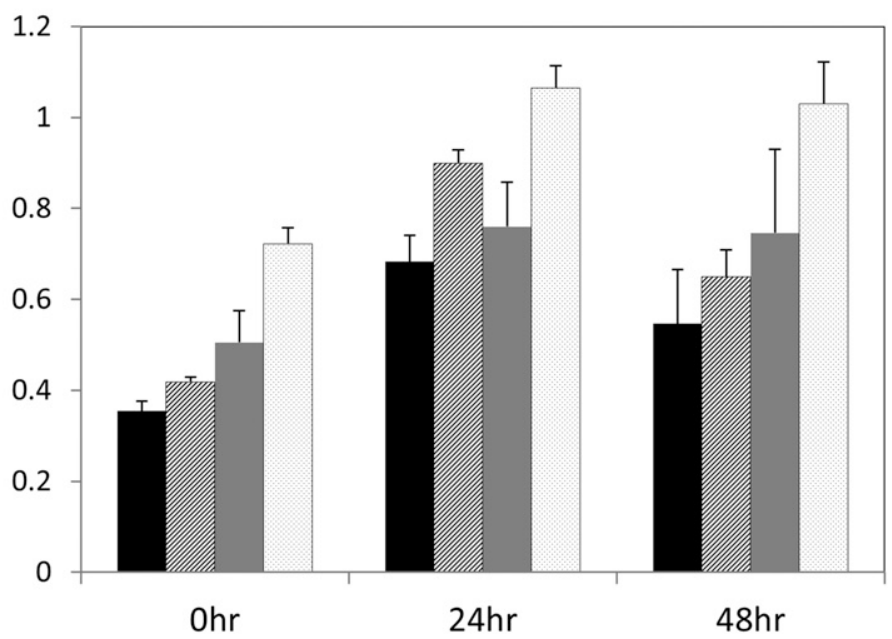

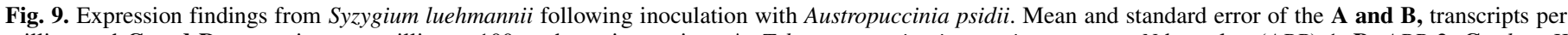

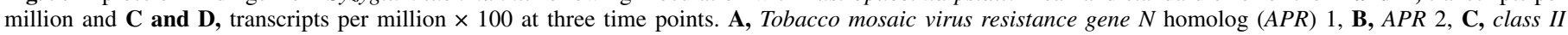

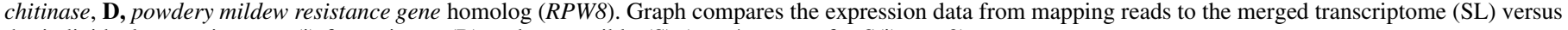
the individual transcriptomes (i) for resistant (R) and susceptible (S) ( $n=4$, except for S(i) $n=3)$. 
of polymers of chitin, important in the structural cell walls of fungi. These enzymes, as well as thaumatin-like proteins, are well known for being constitutively expressed in plants but up-regulated following pathogen challenge and hence are described as pathogenesis-related proteins (Edreva 2005). Chitinase expression was determined to be significantly up-regulated after three days in response to fungal inoculation in E. grandis (Tobias et al. 2017). A homolog for E3 ubiquitinprotein ligase At4g11680 is also significantly up-regulated at 48 hpi in resistant plants. With a major role in targeting proteins for degradation, this suggests an important role, either through the removal of damaged host proteins or the targeting of pathogen proteins (Ardley et al. 2005).

Resistant plants express transcripts involved in the secondary metabolite pathway. A clear gene expression difference between resistant and susceptible plants was the large number of up- regulated transcripts within the phenylpropanoid pathway of secondary metabolites. Secondary metabolites are synthesized by plants and have diverse roles, some of which are antiherbivory and antifungal (Moore et al. 2014). In particular, homologs for phenylalanine ammonia lyase (PAL) were significantly up-regulated at 48 hpi within resistant plants compared with susceptible ones, as well as compared with resistant plants preinoculation. This indicates induction of the first step in phenylpropanoid biosynthesis pathways (Widhalm and Dudareva 2015). Also greatly increased in resistant plants were homologs to cytochrome P450 $98 A$ and cytochrome b5, well known for roles in cutin and suberin biosynthesis as well as responses to biotic stress (Pinot and Beisson 2011). Also within the FDR $<0.05$ cutoff was the disease resistance response protein 206 (DRR206), which had extremely high transcript numbers in resistant plants (mean of 2342 TPM for
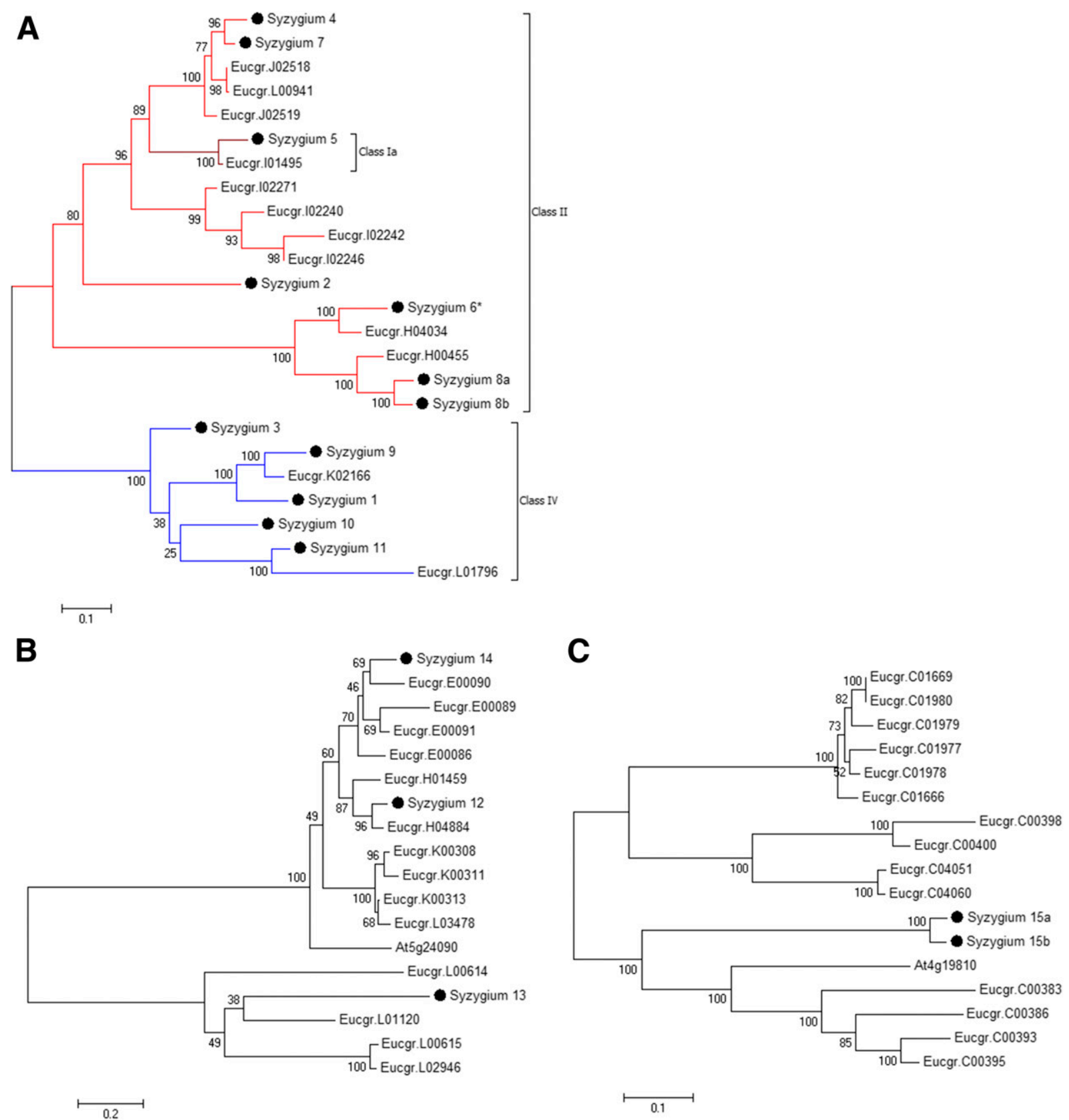

0.1

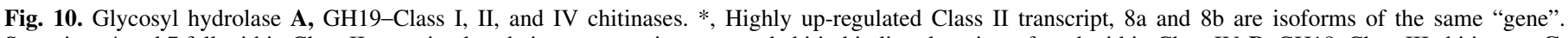

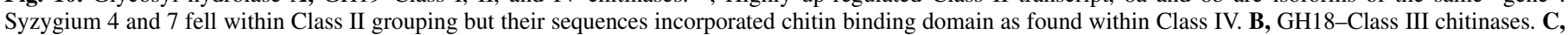

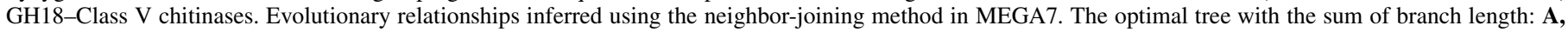

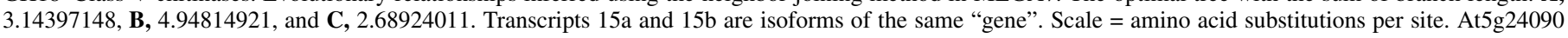

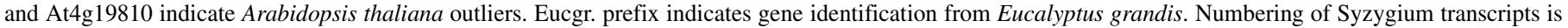
arbitrary. 
$\mathrm{R} 1, \mathrm{R} 2$, and R3) except for R4. While the expression of DRR206 was earlier noted for rapid increase in fungal defense-related proteins (Culley et al. 1995), it is now also known to be important in the phenylpropanoid synthesis pathway.

Very highly expressed transcripts at 24 and 48 hpi within resistant plants compared with susceptible, as well as compared with resistant plants preinoculation, were the cellulose synthase A catalytic subunit 7 and 8 both involved in secondary cell wall formation (Taylor et al. 2000). The rapid increase in these transcripts within resistant plants indicates an active response to incursion.

Susceptible plants have no response to the pathogen. Susceptible plants showed no coordinated systemic response to the pathogen. Similarly low differential transcript numbers were noted for Poplar and the compatible leaf rust, Melampsora larici-populina (Rinaldi et al. 2007). This may indicate pathogen suppression of defense-response genes, as reported in compatible wheat Puccinia striiformis f. sp. tritici interactions (Dobon et al. 2016). At 24 and 48 hpi, susceptible plants responded with only three significantly differentially expressed transcripts. Significant expression differences were the down-regulation of strigolactone esterase D14 homolog and up-regulation of E. grandis zinc finger protein CONSTANS-LIKE 2 and E. grandis protein $L H Y$ homologs.

Novel fused NBS-LRR domains indicate potential for pathogen recognition. Using a hidden Markov model for the conserved NB-ARC domain, it was determined that each plant had different numbers of $N B S$ - $L R R$ type transcripts, though numbers did not correlate with disease resistance or susceptibility. The most abundant fused domains, with NB-ARC, were TIR and LRR domains, both commonly present within this class of resistance genes in eudicotyledons. Transcripts with the Jacalin domain, a mannose binding lectin, were also particularly abundant. Four predicted NBS-LRR type genes within E. grandis also incorporated Jacalin domains (Christie et al. 2016), known to be involved in innate immunity across a broad range of organisms (Rüdiger and Gabius 2002). Two transcripts incorporating the Jacalin domain were present in resistant plants preinoculation in greater quantities $\left(\log _{2}\right.$ fold difference $=4.6$ and 4.5 ). Other highly varied domains were identified including several NB-ARC domains fused with transcription factor (TF) domains such as zinc finger (zf) BED and zf reverse transcription (RVT) domains. These domains may play a role in initiating the transcription of downstream defense-related genes or acting as potential effector decoys, as has been determined in A. thaliana (Le Roux et al. 2015). Integrated NBS-LRR: BED 'decoy' domains have been identified in Poplar (Germain and Seguin 2011) and have also been tested in rice susceptibility to rice blast fungus Magnaporthe oryzae (Kroj et al. 2016). The identified fused TF domains within the $S$. luehmannii transcriptome may therefore be interesting to investigate further. Protein tyrosine kinase domains and Ras domains, both important in cellular signaling, and RPW8 domain, a broad-spectrum powdery mildew resistance gene homolog, were also present across plants (Table 3 ). A recent analysis of RPW8 domains across species indicates conservation, particularly across the Rosales clade (Zhong and Cheng 2016). The localization of RPW8 resistance proteins to the extrahaustorial membrane where they facilitate encasement of haustoria and may trigger hypersensitive response, has been determined in A. thaliana and Brassica oleracea (Berkey et al. 2016). Many species have numerous copies of RPW8 containing genes, however E. grandis has only one (Christie et al. 2016). It is interesting therefore that our data revealed an average of 5.8 RPW8 transcripts within S. luehmannii, suggesting alternative transcripts or variation in evolutionary selection pressures since diverging with $E$. grandis around $65 \mathrm{Ma}$ (Thornhill et al. 2015). Upregulation of $R P W 8$ type transcripts was highest at 24 hpi and greatest in susceptible plants (Fig. 9D).

Chitinases are highly conserved within S. luehmannii. Translated and aligned transcript sequences, identified as GH19 chitinases, were found to be highly conserved across the eight
$S$. luehmannii plants and with E. grandis. This permitted the identification of classes of GH19 genes when compared with E. grandis putative chitinases (Tobias et al. 2017). The chitinase sequence identified as significantly up-regulated in resistant plants was classified as a Class II chitinase based on the phylogenetic grouping (Fig. 10A), with closest homology to E. grandis Eucgr. H04034. The Class IA chitinase, conformed to the domain structure for this class, containing a chitin-binding domain, a GH19 domain and a vacuolar targeting sequence, and was present within all plants. A single 'gene' within each transcriptome for the Class IA conforms to a similar finding within the E. grandis sequence data (Tobias et al. 2017). However, an interesting finding was the presence of two sequences, aligned with Class II chitinases that incorporate chitinbinding domains but lacking vacuolar targeting sequences, suggesting that these might be variants of Class I chitinases. The closest homolog within E. grandis (Eucgr.J02519) does not have a chitin-binding domain. This would suggest that $S$. luehmannii, unlike $E$. grandis, has maintained diversity of this gene class, in line with other woody species (Jiang et al. 2013), perhaps due to evolutionary selection pressures.

Fewer putative GH18 chitinases were identified within S. luehmannii plants, indicating that these enzymes may not be important in responses to $A$. psidii. When aligned with translated putative E. grandis sequences, only three Class III and two Class V were identified within the transcriptome.

Conclusions. When conducting expression studies on nonmodel organisms a number of problems can arise. Genetic diversity is likely to be high between individuals, particularly when wildsourced, as previously noted for eucalypts (Webb et al. 2014). It is possible that genetic diversity can mask expression responses to perturbation that may be highly complex, particularly with regard to plant-pathogen interactions. Additionally, de novo assemblies can be inaccurate with regard to highly variable sequences such as recognition receptors (Steuernagel et al. 2015), which are often involved in defense. Also of note, expression for HR is highly localized in and around infected cells (Morel and Dangl 1997), meaning that mRNA taken from whole leaf samples is likely to be diluted by surrounding cells, suggesting that localized expression differences may be much greater in affected cells. Despite these caveats, by taking a stringent cut-off for the analysis, the results point to a clear relationship between early recognition of the pathogen followed by rapid and global gene expression changes within plants displaying resistant phenotypes. Data from larger samples, combined with an assembled genome for the species, will help to clarify these results.

There are concerns internationally for myrtle rust impacts on commercial industries as well as natural ecosystems, dominated by species in the Myrtaceae. Determining the genetic basis to resistance is important for developing resilient crops, determining suitable management practices for ecologically sensitive myrtaceaous species as well as extending our knowledge on pathogen defense in woody plants. With no comprehensive genome available for either the host or pathogen, the current analysis, based on de novo transcriptome assemblies, compares plant responses at early stages of infection and provides foundational work from which to build knowledge. The identification of a $G$-type lectin receptor-like kinase, exclusively expressed in resistant individuals, as well as two TIR-NBS-LRR-type transcripts that appear to indicate resistance provides a useful starting point for future investigations.

\section{ACKNOWLEDGMENTS}

We thank M. Powrie who generously helped with computational support including writing python scripts that enabled searches within sequence data lists. We would like to acknowledge the University of Sydney HPC service for providing resources that have contributed to the research results. 


\section{LITERATURE CITED}

Ardley, H. C., Robinson, P. A., Ardley, H. C., Robinson, P. A., Michael, D., Oren, M., Wasch, R., Engelbert, D., Robinson, P. A., Ardley, H. C., Hicke, L., Liu, Y., Fallon, L., Lashuel, H. A., Liu, Z., Lansbury, P. T., Scheffner, M., Huibregtse, J. M., Vierstra, R. D., Howley, P. M., Moll, U. M., Petrenko, O., Kishino, T., Lalande, M., Wagstaff, J., Kishino, T., Lalande, M., Wagstaff, J., Matsuura, T., Sutcliffe, J. S., Fang, P., Galjaard, R. J., Jiang, Y. H., Benton, C. S., Rommens, J. M., Beaudet, A. L., Ji, Y., Walkowicz, M. J., Buiting, K., Johnson, D. K., Tarvin, R. E., Rinchik, E. M., Horsthemke, B., Stubbs, L., Nicholls, R. D., Lehman, A. L., Nakatsu, Y., Ching, A., Bronson, R. T., Oakey, R. J., Keiper-Hrynko, N., Finger, J. N., Durham-Pierre, D., Horton, D. B., Newton, J. M., Borden, K. L., Freemont, P. S., Jackson, P. K., Eldridge, A. G., Freed, E., Furstenthal, L., Hsu, J. Y., Kaiser, B. K., Reimann, J. D., Ardley, H. C., Tan, N. G. S., Rose, S. A., Markham, A. F., Robinson, P. A., Capili, A. D., Edghill, E. L., Wu, K., Borden, K. L., Dikic, I., Marmor, M. D., Yarden, Y., Courbard, J. R., Fiore, F., Adelaide, J., Borg, J. P., Birnbaum, D., Ollendorff, V., Morett, E., Bork, P., Marin, I., Lucas, J. I., Gradilla, A. C., Ferrus, A., Kitada, T., Asakawa, S., Hattori, N., Matsumine, H., Yamamura, Y., Minoshima, S., Yokochi, M., Mizuno, Y., Shimizu, N., Shimura, H., Hattori, N., Kubo, S., Mizuno, Y., Asakawa, S., Minoshima, S., Shimizu, N., Iwai, K., Chiba, T., Tanaka, K., Suzuki, T., Mizuno, Y., Hattori, N., Mori, H., Suzuki, T., Tanaka, K., Chung, K. K. K., Zhang, Y., Lim, K. L., Tanaka, Y., Huang, H., Gao, J., Ross, C. A., Dawson, V. L., Dawson, T. M., Huynh, D. P., Scoles, D. R., Nguyen, D., Pulst, S. M., Imai, Y., Soda, M., Hatakeyama, S., Akagi, T., Hashikawa, T., Nakayama, K.-I., Takahashi, R., Staropoli, J. F., McDermott, C., Martinat, C., Schulman, B., Demireva, E., Abeliovich, A., Petroski, M. D., Deshaies, R. J., Vodermaier, H. C., Gieffers, C., Maurer-Stroh, S., Eisenhaber, F., Peters, J. M., Passmore, L. A., McCormack, E. A., Au, S. W., Paul, A., Willison, K. R., Harper, J. W., Barford, D., Cyr, D. M., Hohfeld, J., Patterson, C., Hatakeyama, S., Nakayama, K. I., Shirmura, H., Schwartz, D., Gygi, S. P., Kisik, K. S., Hatakeyama, S., Matsumoto, M., Kamura, T., Murayama, M., Chui, D.-H., Planel, E., Takahashi, R., Nakayama, K. I., Takshima, A., Hoppe, T., Cassata, G., Barral, J. M., Springer, W., Hutagalung, A. H., Epstein, H. F., and Baumeister, R. 2005. E3 ubiquitin ligases. Essays Biochem. 41:15-30.

Beenken, L. 2017. Austropuccinia: A new genus name for the myrtle rust Puccinia psidii placed within the redefined family Sphaerophragmiaceae (Pucciniales). Phytotaxa 297:53-61.

Berkey, R., Zhang, Y., Ma, X., King, H., Zhang, Q., Wang, W., and Xiao, S. 2016. Homologues of the RPW8 resistance protein are localized to the extrahaustorial membrane that is likely synthesized de novo. Plant Physiol. 173: 600-613.

Bolger, A. M., Lohse, M., and Usadel, B. 2014. Trimmomatic: A flexible trimmer for Illumina sequence data. Bioinformatics 30:2114-2120.

Brewer, P. B., Koltai, H., and Beveridge, C. A. 2013. Diverse roles of strigolactones in plant development. Mol. Plant 6:18-28.

Brown, T. 2010. Counting reads for RNAseq. ANGUS 2.0 Doc. http://angus. readthedocs.io/en/2013/rnaseq_bwa_counting.html

Butler, J. B., Freeman, J. S., Vaillancourt, R. E., Potts, B. M., Glen, M., Lee, D. J., and Pegg, G. S. 2016. Evidence for different QTL underlying the immune and hypersensitive responses of Eucalyptus globulus to the rust pathogen Puccinia psidii. Tree Genet. Genomes 12:39.

Carnegie, A., Lidbetter, J., Walker, J., Horwood, M., Tesoriero, L., Glen, M., and Priest, M. 2010. Uredo rangelii, a taxon in the guava rust complex, newly recorded on Myrtaceae in Australia. Australas. Plant Pathol. 39:463-466.

Carnegie, A. J., Kathuria, A., Pegg, G. S., Entwistle, P., Nagel, M., and Giblin, F. R. 2016. Impact of the invasive rust Puccinia psidii (myrtle rust) on native Myrtaceae in natural ecosystems in Australia. Biol. Invasions 18:127-144.

Carnegie, A. J., and Lidbetter, J. R. 2012. Rapidly expanding host range for Puccinia psidii sensu lato in Australia. Australas. Plant Pathol. 41:13-29.

Césari, S., Kanzaki, H., Fujiwara, T., Bernoux, M., Chalvon, V., Kawano, Y., Shimamoto, K., Dodds, P., Terauchi, R., and Kroj, T. 2014. The NB-LRR proteins RGA4 and RGA5 interact functionally and physically to confer disease resistance. EMBO J. 33:1941-1959.

Chen, X., Shang, J., Chen, D., Lei, C., Zou, Y., Zhai, W., Liu, G., Xu, J., Ling, Z., Cao, G., Ma, B., Wang, Y., Zhao, X., Li, S., and Zhu, L. 2006. A B-lectin receptor kinase gene conferring rice blast resistance. Plant J. 46:794-804.

Christie, N., Tobias, P. A., Naidoo, S., and Külheim, C. 2016. The Eucalyptus grandis NBS-LRR gene family: Physical clustering and expression hotspots. Front. Plant Sci. 6:1-16.

Clarke, M. 2013. Native Foods R\&D Priorities and Strategies 2013-2018. Rural Ind. Res. Dev. Corp. 13/023:1-42.

Conesa, A., and Götz, S. 2008. Blast2GO: A comprehensive suite for functional analysis in plant genomics. Int. J. Plant Genomics 2008:1-12.

Cook, D. E., Mesarich, C. H., and Thomma, B. P. H. J. 2015. Understanding plant immunity as a surveillance system to detect invasion. Annu. Rev. Phytopathol. 53:541-563.
Culley, D. E., Horovitz, D., and Hadwiger, L. 1995. Molecular characterization of disease-resistance response gene DRR206-d from Pisum sativum (L.). Plant Physiol. 107:301-302.

Demšar, J., Curk, T., Erjavec, A., Gorup, Č., Hočevar, T., Milutinovič, M., Možina, M., Polajnar, M., Toplak, M., Starič, A., Štajdohar, M., Umek, L., Žagar, L., Žbontar, J., Žitnik, M., and Zupan, B. 2013. Orange: Data mining toolbox in Python. J. Mach. Learn. Res. 14:2349-2353.

Dobon, A., Bunting, D. C. E., Cabrera-Quio, L. E., Uauy, C., and Saunders, D. G. O. 2016. The host-pathogen interaction between wheat and yellow rust induces temporally coordinated waves of gene expression. BMC Genomics 17:380.

Eddy, S. R., and Wheeler, T. J. 2015. HMMER User Guide. V3.1b2:120.

Edreva, A. 2005. Pathogenesis-related proteins: Research progress in the last 15 years. Gen. Appl. Plant Physiol. 31:105-124.

Finn, R. D., Mistry, J., Schuster-Bockler, B., Griffiths-Jones, S., Hollich, V., Lassmann, T., Moxon, S., Marshall, M., Khanna, A., and Durbin, R. 2006. Pfam: Clans, web tools and services. Nucleic Acids Res. 34:D247-D251.

Fu, L., Niu, B., Zhu, Z., Wu, S., and Li, W. 2012. CD-HIT: Accelerated for clustering the next-generation sequencing data. Bioinformatics 28 : 3150-3152.

Fu, Z. Q., and Dong, X. 2013. Systemic acquired resistance: turning local infection into global defense. Annu. Rev. Plant Biol. 64:839-863.

Germain, H., and Seguin, A. 2011. Innate immunity: Has poplar made its BED? New Phytol. 189:678-687.

Giblin, F., and Carnegie, A. 2014. Puccinia psidii (myrtle rust)-Australian host list. Version current 24 September 2014. Australian Network for Plant Conservation. www.anpc.asn.au/myrtle-rust

Glen, M., Alfenas, C., Zauza, E. V., Wingfield, M. J., and Mohammed, C. 2007. Puccinia psidii: A threat to the Australian environment and economy-A review. Australas. Plant Pathol. 36:1.

Goodstein, D. M., Shu, S., Howson, R., Neupane, R., Hayes, R. D., Fazo, J., Mitros, T., Dirks, W., Hellsten, U., Putnam, N., and Rokhsar, D. S. 2012. Phytozome: A comparative platform for green plant genomics. Nucleic Acids Res. 40:D1178-D1186.

Grabherr, M. G., Haas, B. J., Yassour, M., Levin, J. Z., Thompson, D. A., Amit, I., Adiconis, X., Fan, L., Raychowdhury, R., Zeng, Q., Chen, Z., Mauceli, E., Hacohen, N., Gnirke, A., Rhind, N., di Palma, F., Birren, B. W., Nusbaum, C., Lindblad-Toh, K., Friedman, N., and Regev, A. 2011. Full-length transcriptome assembly from RNA-Seq data without a reference genome. Nat. Biotechnol. 29:644-652.

Haas, B. J., Papanicolaou, A., Yassour, M., Grabherr, M., Blood, P. D., Bowden, J., Couger, M. B., Eccles, D., Li, B., Lieber, M., Macmanes, M. D., Ott, M., Orvis, J., Pochet, N., Strozzi, F., Weeks, N., Westerman, R., William, T., Dewey, C. N., Henschel, R., Leduc, R. D., Friedman, N., and Regev, A. 2013. De novo transcript sequence reconstruction from RNA-seq using the Trinity platform for reference generation and analysis. Nat. Protoc. 8:1494-1512.

Jiang, C., Huang, R. F., Song, J. L., Huang, M. R., and Xu, L. A. 2013. Genome-wide analysis of the chitinase gene family in Populus trichocarpa. J. Genet. 92:121-125.

Johnson, L. S., Eddy, S. R., and Portugaly, E. 2010. Hidden Markov model speed heuristic and iterative HMM search procedure. BMC Bioinform 11: 431.

Kearse, M., Moir, R., Wilson, A., Stones-Havas, S., Cheung, M., Sturrock, S., Buxton, S., Cooper, A., Markowitz, S., Duran, C., Thierer, T., Ashton, B., Meintjes, P., and Drummond, A. 2012. Geneious Basic: An integrated and extendable desktop software platform for the organization and analysis of sequence data. Bioinformatics 28:1647-1649.

Kim, W. C., Ko, J. H., Kim, J. Y., Kim, J., Bae, H. J., and Han, K. H. 2013. MYB46 directly regulates the gene expression of secondary wall-associated cellulose synthases in Arabidopsis. Plant J. 73:26-36.

Kriticos, D. J., Morin, L., Leriche, A., Anderson, R. C., and Caley, P. 2013. Combining a climatic niche model of an invasive fungus with its host species distributions to identify risks to natural assets: Puccinia psidii sensu lato in Australia. PLoS One 8:e64479.

Kroj, T., Chanclud, E., Michel-Romiti, C., Grand, X., and Morel, J. 2016. Integration of decoy domains derived from protein targets of pathogen effectors into plant immune receptors is widespread. New Phytol. 210: 618-626.

Kullan, A. R., van Dyk, M. M., Hefer, C., Jones, N., Kanzler, A., and Myburg, A. A. 2012. Genetic dissection of growth, wood basic density and gene expression in interspecific backcrosses of Eucalyptus grandis and E. urophylla. BMC Genet. 13:60.

Kumar, S., Stecher, G., and Tamura, K. 2016. MEGA7: Molecular Evolutionary Genetics Analysis version 7.0 for bigger datasets. Mol. Biol. Evol. 33:1870-1874.

Langmead, B., Trapnell, C., Pop, M., and Salzberg, S. L. 2009. Ultrafast and memory-efficient alignment of short DNA sequences to the human genome. Genome Biol. 10:R25. 
Le Roux, C., Huet, G., Jauneau, A., Camborde, L., Trémousaygue, D., Kraut, A., Zhou, B., Levaillant, M., Adachi, H., Yoshioka, H., Raffaele, S., Berthomé, R., Couté, Y., Parker, J. E., and Deslandes, L. 2015. A receptor pair with an integrated decoy converts pathogen disabling of transcription factors to immunity. Cell 161:1074-1088.

Li, H., Handsaker, B., Wysoker, A., Fennell, T., Ruan, J., Homer, N., Marth, G., Abecasis, G., and Durbin, R. 2009. The Sequence Alignment/Map format and SAMtools. Bioinformatics 25:2078-2079.

Li, W., Jaroszewski, L., and Godzik, A. 2001. Clustering of highly homologous sequences to reduce the size of large protein databases. Bioinform. Appl. Note 17:282-283.

Liang, H., Staton, M., Xu, Y., Xu, T., and Leboldus, J. 2014. Comparative expression analysis of resistant and susceptible Populus clones inoculated with Septoria musiva. Plant Sci. 223:69-78.

Liu, J.-J., Sturrock, R. N., and Benton, R. 2013. Transcriptome analysis of Pinus monticola primary needles by RNA-seq provides novel insight into host resistance to Cronartium ribicola. BMC Genomics 14:884.

Mamani, E. M. C., Bueno, N. W., Faria, D., Guimarães, L. M. S., Lau, D., Alfenas, A. C., and Grattapaglia, D. 2010. Positioning of the major locus for Puccinia psidii rust resistance (Ppr1) on the Eucalyptus reference map and its validation across unrelated pedigrees. Tree Genet. Genomes 6:953-962.

Mangwanda, R., Myburg, A. A., and Naidoo, S. 2015. Transcriptome and hormone profiling reveals Eucalyptus grandis defence responses against Chrysoporthe austroafricana. BMC Genomics 16:319.

Moore, B. D., Andrew, R. L., Külheim, C., and Foley, W. J. 2014. Explaining intraspecific diversity in plant secondary metabolites in an ecological context. New Phytol. 201:733-750.

Morel, J. B., and Dangl, J. L. 1997. The hypersensitive response and the induction of cell death in plants. Cell Death Differ. 4:671-683.

Morin, L., Aveyard, R., Lidbetter, J. R., and Wilson, P. G. 2012. Investigating the host-range of the rust fungus Puccinia psidii sensu lato across tribes of the family Myrtaceae present in Australia. PLoS One 7:e35434.

Myburg, A. A., Grattapaglia, D., Tuskan, G. A., Hellsten, U., Hayes, R. D., Grimwood, J., Jenkins, J., Lindquist, E., Tice, H., Bauer, D., Goodstein, D. M., Dubchak, I., Poliakov, A., Mizrachi, E., Kullan, A. R. K., Hussey, S. G., Pinard, D., van der Merwe, K., Singh, P., van Jaarsveld, I., Silva-Junior, O. B., Togawa, R. C., Pappas, M. R., Faria, D. a., Sansaloni, C. P., Petroli, C. D., Yang, X., Ranjan, P., Tschaplinski, T. J., Ye, C.-Y., Li, T., Sterck, L., Vanneste, K., Murat, F., Soler, M., Clemente, H. S., Saidi, N., Cassan-Wang, H., Dunand, C., Hefer, C. a., Bornberg-Bauer, E., Kersting, A. R., Vining, K., Amarasinghe, V., Ranik, M., Naithani, S., Elser, J., Boyd, A. E., Liston, A., Spatafora, J. W., Dharmwardhana, P., Raja, R., Sullivan, C., Romanel, E., Alves-Ferreira, M., Külheim, C., Foley, W., Carocha, V., Paiva, J., Kudrna, D., Brommonschenkel, S. H., Pasquali, G., Byrne, M., Rigault, P., Tibbits, J., Spokevicius, A., Jones, R. C., Steane, D. a., Vaillancourt, R. E., Potts, B. M., Joubert, F., Barry, K., Pappas, G. J., Strauss, S. H., Jaiswal, P., Grima-Pettenati, J., Salse, J., Van de Peer, Y., Rokhsar, D. S., and Schmutz, J. 2014. The genome of Eucalyptus grandis. Nature 510:356-362.

Oates, C. N., Külheim, C., Myburg, A. A., Slippers, B., and Naidoo, S. 2015. The transcriptome and terpene profile of Eucalyptus grandis reveals mechanisms of defense against the insect pest, Leptocybe invasa. Plant Cell Physiol. 56:1418-1428.

Pegg, G. S., Brawner, J. T., and Lee, D. J. 2014a. Screening Corymbia populations for resistance to Puccinia psidii. Plant Pathol. 63:425-436.

Pegg, G. S., Giblin, F. R., McTaggart, A. R., Guymer, G. P., Taylor, H., Ireland, K. B., Shivas, R. G., and Perry, S. 2014b. Puccinia psidii in Queensland, Australia: Disease symptoms, distribution and impact. Plant Pathol. 63:1005-1021.

Pinot, F., and Beisson, F. 2011. Cytochrome P450 metabolizing fatty acids in plants: Characterization and physiological roles. FEBS J. 278:195-205.

Quinlan, A. R., and Hall, I. M. 2010. BEDTools: A flexible suite of utilities for comparing genomic features. Bioinformatics 26:841-842.
R Development Core Team. 2011. R: A Language and Environment for Statistical Computing. RDC Team, ed. R Foundation for Statistical Computing, Vienna, Austria 1:409.

Rinaldi, C., Kohler, A., Frey, P., Duchaussoy, F., Ningre, N., Couloux, A., Wincker, P., Le Thiec, D., Fluch, S., Martin, F., and Duplessis, S. 2007. Transcript profiling of poplar leaves upon infection with compatible and incompatible strains of the foliar rust Melampsora larici-populina. Plant Physiol. 144:347-366.

Robinson, M. D., McCarthy, D. J., and Smyth, G. K. 2009. edgeR: A Bioconductor package for differential expression analysis of digital gene expression data. Bioinformatics 26:139-140.

Roy, A., Kucukural, A., and Zhang, Y. 2010. I-TASSER: a unified platform for automated protein structure and function prediction. Nat. Protoc. 5:725-738.

Rüdiger, H., and Gabius, H. J. 2002. Plant lectins: Occurrence, biochemistry, functions and applications. Glycoconj. J. 18:589-613.

Saitou, N., and Nei, M. 1987. The neighbor-joining method: A new method for reconstructing phylogenetic trees. Mol. Biol. Evol. 4:406-25.

Sandhu, K. S., Karaoglu, H., Zhang, P., and Park, R. F. 2015. Simple sequence repeat markers support the presence of a single genotype of Puccinia psidii in Australia. Plant Pathol. 65:1084-1094.

Saucet, S. B., Ma, Y., Sarris, P., Furzer, O. J., Sohn, K. H., and Jones, J. D. G. 2015. Two linked pairs of Arabidopsis TNL resistance genes independently confer recognition of bacterial effector AvrRps4. Nat. Commun. 6:6338.

Steuernagel, B., Jupe, F., Witek, K., Jones, J. D. G., and Wulff, B. H. 2015. NLR-parser: Rapid annotation of plant NLR complements. Bioinformatics 31:1665-1667.

Taylor, N. G., Laurie, S., and Turner, S. R. 2000. Multiple cellulose synthase catalytic subunits are required for cellulose synthesis in Arabidopsis. Plant Cell 12:2529-2540.

Thompson, J. D., Higgins, D. G., and Gibson, T. J. 1994. CLUSTAL W: Improving the sensitivity of progressive multiple sequence alignment through sequence weighting, position-specific gap penalties and weight matrix choice. Nucleic Acids Res. 22:4673-4680.

Thornhill, A. H., Ho, S. Y. W., Külheim, C., and Crisp, M. D. 2015. Interpreting the modern distribution of Myrtaceae using a dated molecular phylogeny. Mol. Phylogenet. Evol. 93:29-43.

Tobias, P. A., Christie, N., Naidoo, S., Guest, D. I., and Külheim, C. 2017. Identification of the Eucalyptus grandis chitinase gene family and expression characterization under different biotic stress challenges. Tree Physiol. 2014:1-18.

Tobias, P. A., Park, R. F., Külheim, C., and Guest, D. I. 2015. Wild-sourced Chamelaucium uncinatum have no resistance to Puccinia psidii (myrtle rust). Australas. Plant Dis. Notes 10:15.

Wang, X., Basnayake, B. M. V. S., Zhang, H., Li, G., Li, W., Virk, N., Mengiste, T., and Song, F. 2009b. The Arabidopsis ATAF1, a NAC transcription factor, is a negative regulator of defense responses against necrotrophic fungal and bacterial pathogens. Mol. Plant-Microbe Interact. 22:1227-1238.

Wang, Z., Gerstein, M., and Snyder, M. 2009a. RNA-Seq: A revolutionary tool for transcriptomics. Nat. Rev. Genet. 10:57-63.

Webb, H., Foley, W. J., and Külheim, C. 2014. The genetic basis of foliar terpene yield: Implications for breeding and profitability of Australian essential oil crops. Plant Biotechnol. 31:363-376.

Westaway, J. O. 2016. The pathogen myrtle rust (Puccinia psidii) in the Northern Territory: First detection, new host and potential impacts. North. Territ. Nat. 27:13-28.

Widhalm, J. R., and Dudareva, N. 2015. A familiar ring to it: Biosynthesis of plant benzoic acids. Mol. Plant 8:83-97.

Zauza, E. V., Alfenas, A., Old, K., Couto, M. F., Graça, R., and Maffia, L. 2010. Myrtaceae species resistance to rust caused by Puccinia psidii. Australas. Plant Pathol. 39:406-411.

Zhong, Y., and Cheng, Z.-M. 2016. A unique RPW8-encoding class of genes that originated in early land plants and evolved through domain fission, fusion, and duplication. Sci. Rep. 6:32923. 